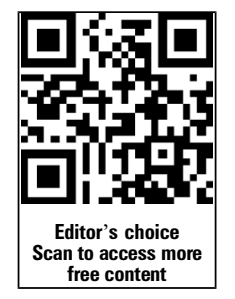

\title{
Exercise and pregnancy in recreational and elite athletes: 2016 evidence summary from the IOC expert group meeting, Lausanne. Part 1-exercise in women planning pregnancy and those who are pregnant
}

\author{
Kari Bø, ${ }_{1}^{1}$ Raul Artal, ${ }^{2}$ Ruben Barakat, ${ }^{3}$ Wendy Brown, ${ }^{4}$ Gregory A L Davies, ${ }^{5}$ \\ Michael Dooley, ${ }^{6}$ Kelly R Evenson, ${ }^{7,8}$ Lene A H Haakstad, ${ }^{9}$ Karin Henriksson-Larsen, ${ }^{10}$ \\ Bengt Kayser, ${ }^{11}$ Tarja I Kinnunen, ${ }^{12,13}$ Michelle F Mottola, ${ }^{14}$ Ingrid Nygaard, ${ }^{15}$ \\ Mireille van Poppel, ${ }^{16}$ Britt Stuge, $^{17}$ Karim M Khan ${ }^{18}$
}

For numbered affiliations see end of article.

\section{Correspondence to}

Professor Kari Bø, Norwegian School of Sport Sciences, Oslo 0806, Norway; kari.bo@nih.no

Accepted 10 March 2016

CrossMark

To cite: $B ø K$, Artal $R$ Barakat $\mathrm{R}$, et al. Br J Sports Med 2016;50:571-589.

\section{BACKGROUND}

Guidelines on physical activity or exercise and pregnancy encourage pregnant women to continue or adopt an active lifestyle during and following pregnancy. ${ }^{1-3}$ Two systematic reviews of pregnancy-related guidelines on physical activity found similarities between recommendations from different countries, but noted that the guidelines differed in focus. ${ }^{4} 5$ The guidelines provided variable guidance on prenatal exercise, or on how pregnant women might approach continuing or adopting sport activities. ${ }^{6}$ However, most guidelines did not include important topics such as prevalence and known risk factors for common pregnancy-related diseases and complaints, and the role of exercise in preventing and treating them.

Importantly, the focus of most previous guidelines has been on healthy pregnant women in the general population, in whom there is almost always a decline in physical activity during pregnancy. ${ }^{78}$ Indeed, a high proportion of pregnant women follow neither physical activity nor exercise guidelines, ${ }^{9}$ putting them at increased risk of obesity, gestational diabetes mellitus (GDM), and other pregnancy-related diseases and complaints. ${ }^{1}$

On the other hand, there are enthusiastic exercisers and elite athletes who often meet and exceed general exercise recommendations for pregnant women, but there are no exercise guidelines specifically for these women. Important questions for such women are unanswered in current guidelines: Which activities, exercises and sports can they perform, for how long and at what intensity, without risking their own health and the health of the fetus? How soon can they return to highintensity training and competition after childbirth?

The IOC and most National Sports Federations encourage women to participate in all Olympic sport disciplines. The IOC promotes high-level performance, and it is also strongly committed to promoting lifelong health among athletes ${ }^{10}$-not just during their competitive sporting careers. With an increasing number of elite female athletes competing well into their thirties, many may wish to become pregnant, and some also want to continue to compete after childbirth. With this background, the IOC assembled an international expert committee to review the literature on physical activity and exercise (1) during pregnancy and (2) after childbirth, using rigorous systematic review and search criteria. ${ }^{11}$ For efficiency, where sex is not specified, the reader should assume that this manuscript about pregnancy and childbirth refers to females (ie, 'the elite athlete who wishes to train at altitude' is used in preference to 'the elite female athlete...').

\section{AIMS}

The September 2015 IOC meeting of 16 experts in Lausanne had three aims. They were to:

1. Summarise common conditions, illnesses and complaints that may interfere with strenuous exercise and competition, during pregnancy and after childbirth;

2. Provide recommendations for exercise training during pregnancy and after childbirth, for highlevel regular exercisers and elite athletes; and

3. Identify major gaps in the literature that limit the confidence with which recommendations can be made.

\section{METHODS}

For each section of the document, a search strategy was performed using search terms such as 'pregnancy' OR 'pregnant' OR 'postpartum' AND 'exercise' OR 'physical activity' OR 'leisure activity' OR 'leisure' OR 'recreation' OR 'recreational activity' or 'physical fitness' OR 'occupational activity' AND terms related to the condition under study (eg, 'gestational diabetes'). Available databases were searched, with an emphasis on PubMed, EMBASE, Cochrane, PEDro, Web of Science and SPORTDiscus. In addition, existing guidelines with reference lists were scanned.

The review of each topic followed the general order: prevalence of the condition in the general pregnant or postpartum population, prevalence in high-level exercisers or elite athletes, risk factors in the general population and in relation to exercise and sport, and effect of preventive and treatment interventions. Level of evidence and grade of recommendations are according to the Cochrane handbook (table 1) for prevention and treatment interventions only. 
Each member of the working group was assigned to be the lead author of one or more topics and 1-3 others were assigned to review each topic. A first full consensus draft was reviewed before and during the 3-day IOC meeting (27-29 September 2015), and a new version of each topic was submitted to the meeting chairs $(\mathrm{KB}$ and $\mathrm{KMK})$ shortly after the meeting. Each topic leader made amendments before sending a new version for comments to the working group.

\section{DEFINITIONS}

Terms used in this review: ${ }^{12}$

\begin{tabular}{|c|c|}
\hline Physical activity & $\begin{array}{l}\text { Any bodily movement produced by the skeletal } \\
\text { muscles that results in a substantial increase over } \\
\text { resting energy expenditure. }\end{array}$ \\
\hline Exercise & $\begin{array}{l}\text { Physical activity that is usually performed on a } \\
\text { repeated basis over an extended period of time } \\
\text { (exercise training) with a specific external objective } \\
\text { such as improvement of fitness, physical performance } \\
\text { or health. }\end{array}$ \\
\hline Mode & $\begin{array}{l}\text { Type of exercise (running, swimming, etc) AND } \\
\text { temporal pattern of activity (continuous or } \\
\text { intermittent activity). }\end{array}$ \\
\hline Intensity & $\begin{array}{l}\text { Absolute or relative (eg, percentage of one repetition } \\
\text { maximum or maximum oxygen consumption: } \mathrm{VO}_{2 \max } / \\
\text { heart rate (HR) reserve). }\end{array}$ \\
\hline Frequency & Number of sessions undertaken in a typical week. \\
\hline Duration & $\begin{array}{l}\text { Minutes or hours of one session or the whole exercise } \\
\text { period ( } 3 \text { months, } 1 \text { year). }\end{array}$ \\
\hline Fitness & $\begin{array}{l}\text { A set of attributes (qualities) relating to the ability to } \\
\text { perform physical activity/exercise. }\end{array}$ \\
\hline $\begin{array}{l}\text { Performance-related } \\
\text { fitness }\end{array}$ & $\begin{array}{l}\text { Those components of fitness that are necessary for } \\
\text { optimal work or sport performance; the individual's } \\
\text { ability in athletic competition, performance or } \\
\text { occupational work. }\end{array}$ \\
\hline Health-related fitness & $\begin{array}{l}\text { A state characterised by (1) an ability to perform daily } \\
\text { activities with vigour and ( } 2 \text { ) demonstration of traits } \\
\text { and capacities that are associated with low risk of } \\
\text { premature development of hypokinetic diseases and } \\
\text { conditions. }\end{array}$ \\
\hline Exerciser & $\begin{array}{l}\text { A person who performs regular strenuous exercise } \\
\text { both for fitness and competition, but not representing } \\
\text { any national team. }\end{array}$ \\
\hline Elite athlete & $\begin{array}{l}\text { A person who is a member of any national team or } \\
\text { other high-level representative team in any sport } \\
\text { organised by a National Sports Federation. }\end{array}$ \\
\hline Postpartum & $\begin{array}{l}\text { In general, the period from childbirth until } 6 \text { weeks } \\
\text { postpartum. For this review, we have extended this } \\
\text { period to } 12 \text { months after childbirth. }\end{array}$ \\
\hline
\end{tabular}

\section{PRECONCEPTION: APPLYING CURRENT KNOWLEDGE TO THE CARE OF THE ELITE ATHLETE}

The goal of preconception care is to optimise the woman's health and knowledge before planning, and conceiving a pregnancy and thus reduce the risk of adverse health effects for the woman, fetus or neonate. Because reproductive capacity spans almost four decades, optimising women's health before and between pregnancies is an ongoing process that requires access to, and the full participation of, all segments of the healthcare system. $^{13}$

Preconception care aims to identify and modify biomedical, behavioural and social risks through preventive management intervention. ${ }^{14}$ The American Academy of Paediatricians and the American College of Obstetrics and Gynaecology classify this care into four categories: ${ }^{13}$ physical assessment, risk
Table 1 Levels of quality of a body of evidence in the GRADE statement

\begin{tabular}{ll}
\hline Underlying methodology & $\begin{array}{l}\text { Quality } \\
\text { rating }\end{array}$ \\
\hline $\begin{array}{l}\text { Randomised trials; or double-upgraded observational studies } \\
\text { Downgraded randomised trials; or upgraded observational } \\
\text { studies }\end{array}$ & $\begin{array}{l}\text { High } \\
\text { Moderate }\end{array}$ \\
$\begin{array}{l}\text { Double-downgraded randomised trials; or observational studies } \\
\text { Triple-downgraded randomised trials; or downgraded } \\
\text { observational studies; or case series/case reports }\end{array}$ & Low \\
\hline
\end{tabular}

assessment, vaccinations and counselling. For the elite athlete, a number of particular areas should be highlighted and addressed.

Increasing age is associated with decreased fertility ${ }^{15}$ and increased rates of chromosomal abnormalities. ${ }^{16}$

To optimise fertility without in vitro fertilisation (IVF), one research group recommends that couples should start attempting conception at no later than 32 years of age if they are planning a one-child family, 27 years for a two-child family or 23 years for three children. If couples accept a $75 \%$ or lower chance of family completion, they can start $4-11$ years later. If IVF is an option, couples can delay trying to conceive until the female partner is 35 years of age or younger for a one-child family, or until 31 years for two children, or 28 years for three children. ${ }^{17}$

This age period coincides with peak performance for many athletes, who may have impaired fertility related to relative energy deficiency in sport (RED-S), ${ }^{18-21}$ a consideration when making reproductive health recommendations to athletes. RED-S refers to impaired physiological function including, but not limited to, metabolic rate, menstrual function, bone health, protein synthesis, immunological health and cardiovascular health caused by relative energy deficiency. ${ }^{18}$ The long-term reproductive repercussions of RED-S for women are unknown and further research is required. ${ }^{18}$ Numerous features of RED-S have a negative impact on fertility. These include disordered eating and the associated hormonal imbalance. The reader interested in this topic is referred to the IOC Consensus Statement on RED-S. ${ }^{18-21}$

\section{Eating disorders, pregnancy and athletes}

There is consistent evidence that the frequency of eating disorders is higher among athletes (20-22\%) than non-athletes (3-9\%), with an especially high prevalence in weight-sensitive sports such as endurance (24\%), aesthetic (42\%) and sports with weight $(30 \%)$ categories. $^{22-25}$ Competitive athletes are constantly under the stress of improving their results and adapting to the sport-specific 'ideal'. Important risk factors for severe eating disorders include pressure to lose weight, the early start of sport-specific training, overtraining, injuries, restriction of food intake and individual vulnerability. ${ }^{22} 25$ In addition, the sport environment and inappropriate coaching behaviour can exacerbate the issue. ${ }^{25}$ Those with a severe eating disorder are at risk for both medical complications and death, with a reported mortality rate between $4 \%$ and $10 \% .^{26}$

Pregnant athletes with an eating disorder, and their offspring, are at particular risk as they compete for limited nutritional resources. To our knowledge, there are no data on prevalence of eating disorders in pregnant athletes.

\section{Complications associated with eating disorders}

Pregnancy complications for women with anorexia nervosa include hyperemesis gravidarum, anaemia, spontaneous abortion, preterm birth (PTB), caesarean section, and postpartum 
depression. ${ }^{27-29}$ In addition, the neonate is at risk for low birth weight (LBW) and small head. ${ }^{30} 31$ Some studies have shown that these infants have developmental disturbances that persist throughout childhood and adulthood compared with children born to mothers without eating disorders. ${ }^{31} 32$ These children are also more prone to develop anxiety, depression and substance abuse. $^{27} 32$

Pregnancy complications associated with bulimia nervosa are similar to those reported with anorexia nervosa. Additional complications include increased risk of vaginal bleeding, hypertension, fetal abnormalities, low Apgar scores, breech delivery and stillbirth. ${ }^{27} 33$

\section{Management and treatment}

If a pregnant athlete were to have symptoms of, or be considered at risk for, abnormal eating behaviour by medical staff, coaches or other off-field team members, the first step would be to refer appropriately (eg, to a nutritionist or psychiatrist, if appropriate). Close follow up by a team of nutrition, maternalfetal medicine and psychiatric specialists is required to optimise maternal and fetal outcomes. ${ }^{27} 34$ In severe cases, management may require hospitalisation.

\section{Conclusion}

The pregnant athlete with a past or current eating disorder should be considered as being at higher risk of pregnancy complications and requires close monitoring by hypertension, miscarriage, difficult labour, premature delivery and intrauterine growth restriction. Hence, they should be monitored closely, including involvement of a multidisciplinary team, emphasising early recognition and treatment of symptoms, meal planning, training regimen adjustments, and evaluation for maternal or fetal consequences of malnutrition.

\section{PREGNANCY}

\section{Anatomical and physiological adaptations to pregnancy during each trimester}

During pregnancy, there are major changes in the body's physiology and morphology. In this section, we highlight how regular or intense exercise influences the pregnancy-related changes. For a comprehensive overview of the physiology of normal pregnancy, unrelated to exercise and sport, we recommend references. ${ }^{35} 36$

\section{Musculoskeletal adaptations to pregnancy}

The expanding uterus displaces the centre of gravity, which results in the woman compensating to avoid falling forward. This may result in progressive lumbar lordosis and anterior rotation of the pelvis on the femur, ${ }^{37}$ though this finding is not uniformly observed. ${ }^{38}$ If there is an increase in lordosis, then an increase in anterior flexion of the cervical spine and abduction of the shoulders also takes place, which may interfere with performance in specific sports. Enlarged breasts also contribute to the shift in the centre of gravity.

During late pregnancy and the early postpartum period, most often there are significant decreases in both the length of the gait cycle and step length, ${ }^{39-43}$ and a significant increase in double support time. ${ }^{40} 4{ }^{44}$ Additionally, single support time is reduced $^{414}$ and step width increased leading to a wider stance. $^{42} 45$

During pregnancy, the anterior tilt of the pelvis increases by approximately $5^{\circ}, 3944$ followed with an increase in hip flexion during stance phase, ${ }^{39} 40$ an increase of knee flexion during the terminal stance phase, ${ }^{41}$ a decrease of knee extension, ${ }^{40}$ and a decrease of ankle dorsiflexion and plantar flexion. ${ }^{39} 40$

Our search revealed no studies on biomechanical changes in regular exercisers or in elite athletes.

How muscle changes with pregnancy

There are few studies on the muscle morphology of pregnant women. Changes in hormone receptors and their regulators may promote changes in skeletal muscle fibre type (from oxidative to glycolytic). ${ }^{46}$

How balance changes with pregnancy

Postural balance is affected after the first trimester of pregnancy. ${ }^{47}$ Subsequently, falling is a common cause of injury in the general pregnant population, and pregnant women are 2-3 times more likely to be injured by falling than are non-pregnant women. $^{47} 48$ Physical activity and exercise may mitigate this risk, but this has not been tested in the research setting.

\section{Cardiorespiratory, metabolic and thermoregulatory adaptations to pregnancy}

Hormones and growth factors are released into the maternal system in early pregnancy by the corpus luteum, placenta and developing embryo. ${ }^{49}$ These trigger a cascade of physiological events that regulate implantation and fetal-placental growth and development, ${ }^{50}$ leading to maternal, placental and fetal adaptations that occur in a normal low-risk pregnancy.

\section{Cardiorespiratory adaptations to pregnancy}

From about the fifth week of gestation, pregnancy induces rapid, progressive and substantial alterations to the cardiovascular system, ${ }^{51}$ which ensure blood supply to the fetus. ${ }^{52}$ Oestrogen-mediated remodelling reduces vascular tone, leading to a primary reduction in afterload and an increase in venous capacitance. ${ }^{51}$ This is reflected in increased resting cardiac output of about $50 \%$ over non-pregnant values. ${ }^{53}$

Remodelling of the heart increases the dimensions of the ventricular cavity ${ }^{54}$ without increasing wall thickness, ${ }^{55}$ increases aortic capacitance ${ }^{56}$ and reduces peripheral vascular resistance. ${ }^{57}$ There is a $15-20 \mathrm{bpm}$ increase in resting HR over non-pregnant values. ${ }^{58}$ Stroke volume also increases by approximately $10 \%$ by the end of the first trimester. ${ }^{59}$ This manifests before significant enhancement in maternal blood volume, ${ }^{51}$ which may increase up to $50 \%$ above pre-pregnancy values by late pregnancy. ${ }^{60} 61$

There are also pregnancy-induced adaptations to the maternal respiratory system. For example, remodelling and expansion of the thoracic cage raises diaphragmatic mid-position; ${ }^{62}$ this decreases residual volume and expiratory reserve volume. ${ }^{63}$ One of the most substantial physiological pregnancy-induced changes, possibly designed to protect against fetal acidosis, ${ }^{64}$ is an increase in respiratory sensitivity to carbon dioxide $\left(\mathrm{CO}_{2}\right)$ early in pregnancy. This increases tidal volume and minute ventilation, which reduces arterial carbon dioxide tension and increases arterial oxygen tension. ${ }^{65}$ These changes create a buffer that protects the fetus from any acute elevations in maternal carbon dioxide levels. ${ }^{66}$

Many pregnant women complain of respiratory discomfort (dyspnoea), especially in late pregnancy, both at rest and after exertion. ${ }^{67}$ Resting oxygen uptake (relative- $\mathrm{mL} / \mathrm{kg} / \mathrm{min}$ ) reflects the increase in body mass during pregnancy, and thus declines slightly during each trimester. ${ }^{35}$ However, during submaximal steady-state exercise, pregnant women's perceptions of respiratory effort and dyspnoea seem to be reduced, ${ }^{68}$ because maternal anatomical and mechanical respiratory adaptations reduce 
airway resistance, preserve breathing mechanics, minimise the effort of ventilation and thus increase minute ventilation. ${ }^{69}$

\section{Effect of posture on maternal and fetal cardiovascular dynamics}

Supine posture leads to compression of the inferior vena cava by the pregnant uterus, which, in turn, decreases stroke volume, end-diastolic volume index and left ventricular ejection time, with decelerations in maternal HR. ${ }^{70}$ Being motionless (including standing and certain yoga positions) or exercising in the supine position, may decrease venous return and cause hypotension in $10-20 \%$ of pregnant women. ${ }^{70-72}$ One small study has reported that although uterine blood flow also decreased during supine exercise, this decrease was half that seen during supine rest. If symptomatic, women should avoid the supine position. ${ }^{72}$ There are no studies on the effect of exercise in the supine position during pregnancy in elite athletes.

\section{Metabolic adaptations in a normal pregnancy}

The major energy substrate for growth of the fetoplacental unit is maternal blood glucose, and thus maternal metabolism adapts to supply adequate glucose. ${ }^{73}$ A cascade of hormonal events increases maternal blood glucose, decreases liver glycogen storage, elevates liver glucose release ${ }^{74}$ and increases maternal insulin levels. ${ }^{75}$ This increases insulin resistance in skeletal muscle $^{76}$ and thus decreases maternal utilisation of glucose in peripheral tissues, which leaves more maternal glucose for fetal use. $^{77}$ The fetoplacental unit can use as much as $30-50 \%$ of the maternal glucose pool in late gestation. ${ }^{78}$

Changes in responsiveness of the maternal pancreatic $\beta$-cell that lead to insulin resistance occur in concert with growth of the fetoplacental unit, as hormones such as human placental lactogen, progesterone, cortisol and prolactin are released. ${ }^{79}$ Early in pregnancy, maternal body fat is stored, due to the lipogenic action of higher maternal insulin concentrations. ${ }^{80}$ These adipose stores may provide an alternative energy source for the mother later in pregnancy, and preserve maternal blood glucose for fetal use. ${ }^{81}$

\section{Thermoregulatory adaptations to pregnancy}

The fetal neural tube is formed 35-42 days from the last menstrual period, and therefore exposure to increases in temperature after this time should not affect the risk of neural tube defects. ${ }^{82}$

During neural tube development, raising body core temperature above $103^{\circ} \mathrm{F}\left(39^{\circ} \mathrm{C}\right)$ can increase the risk of fetal (neural tube defect) abnormalities. Exercising in pregnancy at $60-70 \%$ of $\mathrm{VO}_{2 \max }$ in a controlled environment for up to $60 \mathrm{~min}$ does not raise core temperature above $38^{\circ} \mathrm{C}$. ${ }^{83}$ Higher body core temperature could be reached during strenuous exercise, such as marathon running, or exercising outdoors in hot and humid weather. However, this has not be evaluated in elite pregnant athletes.

Thermoregulation steadily improves during pregnancy, as reflected by a gradual decline in rectal temperature. ${ }^{84} 85$ As pregnancy advances, a downward shift in body temperature threshold initiates sweating, resulting in evaporative heat loss starting at a lower body temperature. ${ }^{84}$ The improved heat dissipation at rest may be due to decreased vascular tone, with increased circulation to the skin, ${ }^{86}$ augmentation of minute ventilation and plasma volume expansion. ${ }^{84}$ Maternal heat dissipation is vital because fetal metabolism generates heat, and fetal temperature depends on maternal temperature, fetal metabolism and uterine blood flow ${ }^{85}$ (figure 1).

\section{Nutritional requirements for normal pregnancy}

Pregnancy increases a woman's requirements for energy, many nutrients and fluid. This permits growth and development of the fetus and deposition of maternal tissue stores. ${ }^{87}$ Additional energy is needed specifically for development of the fetus, placenta, amniotic fluid, uterus, breasts, adipose tissue, and the increased volumes of blood and extracellular fluid. ${ }^{87}$ The additional energy need for pregnant women with a mean GWG of $12 \mathrm{~kg}$ is estimated to be:

- $325 \mathrm{MJ}(77700 \mathrm{kcal})$ in total and $375 \mathrm{~kJ} /$ day (90 kcal/day) for the first trimester,

- $1200 \mathrm{~kJ} /$ day $(287 \mathrm{kcal} /$ day $)$ for the second trimester, and

- $1950 \mathrm{~kJ} /$ day $(466 \mathrm{kcal} /$ day) for the third trimester of pregnancy. ${ }^{88}$

Energy expenditure is likely to remain high among pregnant elite athletes who continue to train during pregnancy and the total energy intake required will depend on the type, frequency, intensity and duration of the activities performed. An exercising woman can monitor whether she has appropriate energy intake by comparing her weight gain and body mass index (BMI) with the Institute of Medicine (IOM) recommendations (table 2). ${ }^{89}$

\section{Endurance (including altitude), resistance and flexibility training during pregnancy}

Exercise training in pregnant women is influenced by the physiological changes described in the preceding sections. Broadly speaking, women with low-risk pregnancies can undertake the major types of training while pregnant.

\section{Endurance}

Among recreational athletes, there were no differences in aerobic fitness (absolute $\mathrm{VO}_{2 \max }$ ) tested during the past 2 months of a singleton pregnancy and again $6-8$ weeks postpartum. $^{90}$ In more highly conditioned athletes, a moderate-to-high level of exercise during and after pregnancy may lead to an increase in $\mathrm{VO}_{2 \max }$ in the region of $5-10 \%$ after pregnancy. ${ }^{9091}$ Improved anaerobic working capacity is also better preserved in fitter subjects. ${ }^{92}$ Taken together, these studies indicate that a woman's aerobic fitness will stay the same or improve slightly during pregnancy if she continues to exercise as her maternal symptoms permit.

\section{Measuring performance during pregnancy: testing $\mathrm{VO}_{2 \max }$} submaximal tests and HR monitoring

Three standard tests of near maximum exercise capacity (ie, (1) peak $\mathrm{VO}_{2}$ test, (2) true $\mathrm{VO}_{2 \max }$ test ${ }^{83} 93-95$ and (3) tests ending at volitional fatigue $)^{96-100}$ exist. Harmful events have been

Table 2 Recommendations for total weight gain range in singleton pregnancies by pre-pregnancy body mass index (BMI) (Institute of Medicine) ${ }^{89}$

\begin{tabular}{|c|c|c|c|c|}
\hline $\begin{array}{l}\text { Pre-pregnancy } \\
\text { BMI }\left(\mathbf{k g} / \mathrm{m}^{2}\right)\end{array}$ & & $\begin{array}{l}\text { Total } \\
\text { weight } \\
\text { gain } \\
\text { (lbs) }\end{array}$ & $\begin{array}{l}\text { Total } \\
\text { weight } \\
\text { gain } \\
(\mathrm{kg})\end{array}$ & $\begin{array}{l}\text { Weekly weight gain } \\
\text { range in the second } \\
\text { and third trimester, } \\
\text { lbs }(\mathrm{kg})\end{array}$ \\
\hline$<18.5$ & Underweight & $28-40$ & $12.5-18.0$ & $1.0-1.3(0.44-0.58)$ \\
\hline $18.5-24.9$ & $\begin{array}{l}\text { Normal } \\
\text { weight }\end{array}$ & $25-35$ & $11.5-16.0$ & $0.8-1.0(0.35-0.50)$ \\
\hline $25.0-29.9$ & Overweight & $15-25$ & $7.0-11.5$ & $0.5-0.7(0.23-0.33)$ \\
\hline$\geq 30.0^{*}$ & Obese & $11-20$ & $5.0-9.0$ & $0.4-0.6(0.17-0.27)$ \\
\hline
\end{tabular}


Figure 1 Flow chart of maternal, placental and fetal adaptations that occur in a low-risk pregnancy to protect the fetus from potential risks of maternal exercise. The solid arrows represent potential effects of maternal exercise. The dashed arrows represent fetal, placental and maternal adaptations that occur in a low-risk pregnancy to counterbalance these potential maternal exercise effects (adapted with permission from Mottola ${ }^{35}$ ).

\section{EFFECTS OF MODERATE MATERNAL EXERCISE}
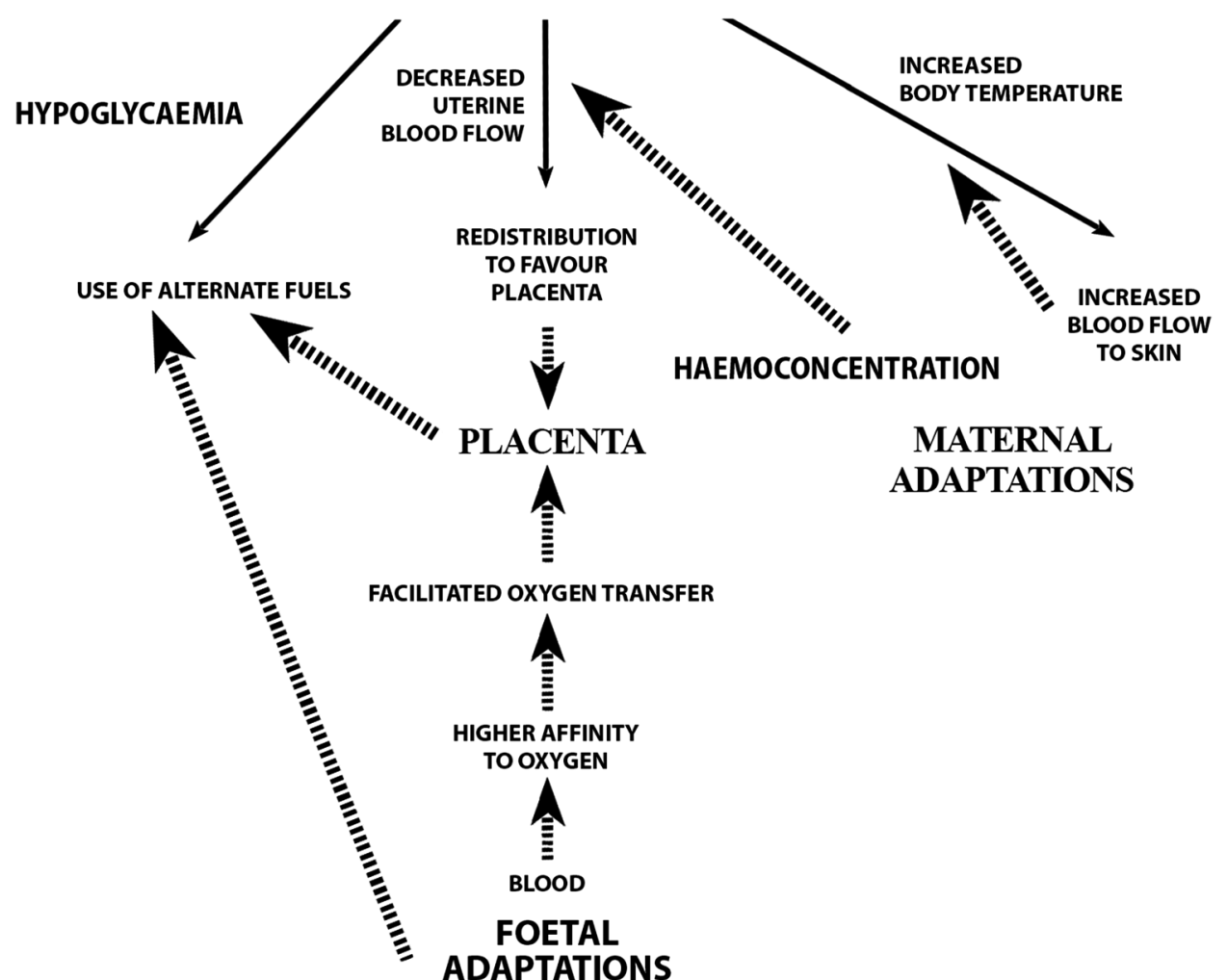

reported for neither mother nor fetus after these tests. However, it is not ethical to test pregnant women to 'failure'. Studies show transient fetal bradycardia when the pregnant elite athlete exercises at above $90 \%$ of maximal maternal HR, ${ }^{101-103}$ but whether these transient fetal HR changes influence neonatal outcomes is unknown. To be appropriately cautious, maximal $\mathrm{VO}_{2}$ testing and exercise above $90 \%$ of $\mathrm{VO}_{2}$ max is not recommended, except in highly supervised (research) settings.

An alternative to $\mathrm{VO}_{2 \max }$ testing during pregnancy is to predict target HRs for training from $\mathrm{VO}_{2 \text { peak }}$ tests ${ }^{100}$ or to predict $\mathrm{VO}_{2 \max }$ from submaximal testing. ${ }^{104-106}$ Target HR ranges do exist-based on age-that were calculated from fit women at 16-20 weeks of pregnancy who had a $\mathrm{VO}_{2}$ peak of $>27.2 \mathrm{~mL} / \mathrm{kg} / \mathrm{min}$ (women aged 20-29 years) and $>26.1 \mathrm{~mL} /$ $\mathrm{kg} / \mathrm{min}$ (women aged 30-39 years). The target HR ranges were based on $60-80 \%$ of measured $\mathrm{VO}_{2}$ peak values and are listed as $145-160 \mathrm{bpm}$ (women aged 20-29 years) and 140-156 bpm (women aged $30-39$ years). ${ }^{100}$ Given the range of sports in which pregnant elite athletes participate, if desired, these target HRs should be calculated on an individual basis.

Testing with ventilatory analyses (eg, expiratory volume/ $\mathrm{VO}_{2}$ ) is often used to determine target zones for distance and interval training in elite athletes, ${ }^{107}$ and could provide pregnant women with an alternative form of submaximal exercise testing. If an elite athlete wished to continue training based on ventilatory threshold test results, she can be assured that during mild or moderate exercise the RER (respiratory exchange) is not significantly different in pregnant women than in non-pregnant women. ${ }^{108}$

During strenuous exercise, the RER rate is lower for the pregnant woman. ${ }^{81}$ Pregnancy is associated with a mild alkalosis, by increasing respiration at a given metabolic rate. ${ }^{66}$ The increased respiration causes the woman to expire more $\mathrm{CO}_{2}$ than normal. This makes the RER increase towards 1.0, which, in the nonpregnant athlete, suggests use of carbohydrate stores. However, in the pregnant athlete, this response is not related specifically to metabolism, and this may limit the use of RER to determine substrate and training zones for more intense exercise in pregnant women. 109110

\section{Borg scale}

During pregnancy, Borg's ratings of perceived exertion (RPE) scale does not correlate strongly with HR. ${ }^{111} \mathrm{HR}$ predicted from RPE is significantly underestimated in the second trimester during walking (ie, actual mean $\mathrm{HR}$ is greater than predicted HR by $16 \mathrm{bpm})$, aerobics classes $(15 \mathrm{bpm})$ and circuit training (18 bpm). In the third trimester, HR while cycling and during aerobics classes are underestimated by a mean of 16 and $11 \mathrm{bpm}$, respectively, but maximal individual HR underestimations may be up to $54 \mathrm{bpm} .{ }^{111}$ A woman who uses RPE as a guide may be exercising at a much higher HR than her RPE would suggest. If an elite athlete is trying to keep her HR within a 'safe' range, RPE should not be used as the only measure of exercise intensity, particularly from the second trimester. The athlete should measure HR directly.

Intensity of endurance training during pregnancy

Recent studies have shown that most recreational and competitive runners voluntarily reduce their training volume during pregnancy and fewer than one-third continue to run during the third trimester. ${ }^{112}$ If a woman runs in the third trimester, the intensity of her run is generally reduced. ${ }^{112}$

Endurance training produces measurable fitness improvement in pregnant women. $\mathrm{VO}_{2 \text { peak }}$ is higher in fit pregnant women 
(>27.2 and $>26.1 \mathrm{~mL} / \mathrm{kg} / \mathrm{min}$ for ages $20-29$ and 30-39 years, respectively), than in unfit non-pregnant women $(<21.0$ and $\leq 19.6 \mathrm{~mL} / \mathrm{kg} / \mathrm{min}$, respectively). ${ }^{100}$ Athletes of national and international calibre, but representing a range of different sports including rhythmic gymnastics (which is not an endurance sport), had a $\mathrm{VO}_{2 \max }$ range of $38.5-52.6 \mathrm{~mL} / \mathrm{kg} / \mathrm{min}$ at $15-19$ weeks of gestation, while maintaining up to $8.4 \mathrm{~h} /$ week of vigorous high-volume exercise. ${ }^{91}$ These findings cannot, however, be directly compared with those of today's non-pregnant female endurance athletes, many of whom have $\mathrm{VO}_{2 \max }$ in the range of $68-76 \mathrm{~mL} / \mathrm{kg} / \mathrm{min} .^{113}$

\section{Exercise at altitude during pregnancy}

Elite endurance athletes regularly train at altitude. Whether the pregnant athlete will (1) benefit from this and (2) not compromise her health or that of the fetus is based on isolated observations and a handful of studies. No study has explored the limits of combined exercise and altitude exposure in pregnancy. ${ }^{114}$

To test the level of fetal tolerance and responses to an oxygen reduced environment, symptom-limited $\mathrm{VO}_{2 \max }$ exercise tests were conducted in seven healthy pregnant women at 33-34 weeks gestation at sea level, and within a week, also at an altitude of 6000 feet, after a rapid ascent. Although the lowlander participants had some limitations to maximal aerobic capacity, there were no ominous fetal responses. ${ }^{115}$ There are no studies on pregnant endurance elite athletes exercising at high altitudes (cross-country skiers and runners). The theoretical concern about training at altitude while pregnant is that hypoxia and exercise both decrease blood flow to the uterus, and thus contribute to a decrease in fetal arterial oxygen saturation. Thus, while acknowledging the lack of data, it seems advisable to refrain from high-intensity training regimes at altitudes greater than $1500-2000 \mathrm{~m}^{116}$

\section{Strength training}

Light-to-moderate weight training with free weights or weight machines generally has no adverse health effects during pregnancy. ${ }^{71}$ 117-119 Large strength gains have been reported in apparently healthy pregnant women who adopted strength training twice per week for 12 weeks during pregnancy $(36 \%$ for leg press, 39\% for leg curl, 39\% for lat pull down, $41 \%$ for lumbar extension and 56\% for leg extension). Training was associated with a $14 \%$ increase in lumbar endurance. ${ }^{120}$

However, the training doses used in those studies are not comparable to the strenuous weight training performed by some elite athletes. Women who are considering heavy strength training in pregnancy should understand that the Valsalva manoeuvre used during weight training precipitates a rapid increase in blood pressure and intra-abdominal pressure, and therefore may temporarily decrease blood flow to the fetus. ${ }^{37} 121122$ The repercussions to the fetus of these temporary changes remain unknown. In addition, those athletes participating in heavy strength training should acknowledge that large increases in intra-abdominal pressure may harm the pelvic floor support, which may increase the risk of urinary (UI) or anal incontinence (AI) or pelvic organ prolapse (POP) during or after pregnancy. ${ }^{123}$ Overall, there is sparse knowledge on strenuous strength training in the general pregnant population and no studies on pregnant elite athletes have been conducted.

\section{Flexibility training}

Owing to increased levels of relaxin during pregnancy it has been stated that pregnant women are more lax and have more joint instability. ${ }^{124}$ Neither on the general pregnant population nor on high level exercisers/elite athletes could we find studies measuring range of motion during pregnancy. In addition, no studies were found on the effect of flexibility training during pregnancy.

\section{Sports to avoid during pregnancy}

High-risk sports can be divided into those with risk of trauma (eg, from a collision or being hit by something (eg, hockey stick) or falling), and those with physiological risk factors (eg, scuba diving). In relation to maternal trauma, placental abruption leading to acute or chronic fetal hypoxia or death, may occur. Although lots of the available data on this topic have been extrapolated from pregnant women in motor vehicle accidents, ${ }^{125-127}$ risks also exist in sports where there may be collision or sudden deceleration. An exhaustive list cannot be created, but examples include bobsledding, luge, equestrian (eg, eventing) activities, pole vaulting, ice hockey and downhill ski racing. ${ }^{5}$

In relation to physiological risk, pregnant women should refrain from diving, because the fetus is not protected from decompression problems and is at risk of malformation and gas embolism after decompression disease. ${ }^{128} 129$

\section{Clinical issues in pregnancy with a focus on exercising women: common complaints and diagnoses-prevention and treatment options}

In this section, we highlight the major symptoms of pregnancy and explore medical issues, with a special focus on high-level regular exercisers and elite athletes.

\section{Nausea}

\section{Definition}

Nausea is a feeling of sickness without actual vomiting. Retching (or dry heaving, without expulsion of stomach contents) has been described as a distinct symptom that has been increasingly measured separately to vomiting and nausea. ${ }^{130} 131$

Morning sickness is a misnomer as it can occur at any time of the day. Pregnant women experience nausea, vomiting and retching mostly in the first 6-12 weeks, but in $20 \%$ it can continue up until 20 weeks, or beyond. ${ }^{132} 133$

Hyperemesis gravidarum is characterised by severe and persistent vomiting, intractable vomiting associated with weight loss of more than $5 \%$ of pre-pregnancy weight, dehydration and electrolyte imbalance, which may lead to hospitalisation. ${ }^{134} \mathrm{~A}$ detailed expert review on nausea and vomiting was published in the $B M J$ by Jarvis and Nelson-Piercy. ${ }^{135}$

\section{Prevalence}

Nausea and vomiting are common in early pregnancy, with prevalence rates of between $50 \%$ and $80 \%$ for nausea, and $50 \%$ for vomiting and retching. ${ }^{134} 136$ Hyperemesis gravidarum is less common, affecting about $1 \%$ of pregnancies. ${ }^{137}$ No studies on prevalence among elite athletes were found; however, it is intuitive that pregnant elite athletes with severe nausea or vomiting will not be able to train at usual levels.

The exact reasons for nausea, vomiting and retching in pregnancy remain unknown, but they are thought to be associated with rising levels of human chorionic gonadotrophin (HCG) or oestrogen. ${ }^{138}$ Conditions with higher levels of HCG (multiple pregnancies and molar pregnancies) have been associated with more nausea and vomiting in pregnancy.

Social, physiological and cultural influencing factors have also been studied. ${ }^{139-141}$ For example, nausea and vomiting in pregnancy may lead to considerable psychosocial stress, through altered family, social and occupational functioning. ${ }^{142-144}$ Some 
studies have shown that women with a history of eating disorders are more likely to develop nausea and vomiting in pregnancy. ${ }^{135}$

Helicobacter pylori seropositivity is also associated with nausea and vomiting in pregnancy. ${ }^{145}$ In 105 women exposed to H. pylori, there was a dose-dependent link between IgG and severity of hyperemesis gravidarum. ${ }^{146}$ The clinical implications of this are yet to be established. In patients who do not respond to medical therapy, one might consider investigating for H. pylori as a potentially treatable risk factor.

\section{Differential diagnosis of nausea and vomiting in pregnancy}

Hyperemesis gravidarum is a diagnosis of exclusion that requires systematic history-taking and a thorough clinical assessment. ${ }^{135}$ The differential diagnosis includes other gastrointestinal pathologies including gastritis, appendicitis, cholecystitis and pancreatitis. Other pathologies that should be excluded include urinary tract infections; hyperthyroidism; neurological disorders (eg, migraine); and ear, nose and throat disease (eg, Meniere's disease and vestibular dysfunction). ${ }^{135}$ Clinicians should be alert for eating disorders such as bulimia, which is more common in elite athletes than in non-athletes and may mimic hyperemesis gravidarum. ${ }^{25}$

Management of nausea and vomiting in pregnancy

Weight loss, dehydration and electrolyte imbalances are wellrecognised complications of severe nausea and vomiting in pregnancy. ${ }^{135}$ In the most severe cases, fetal growth restriction and prematurity are also recognised complications. ${ }^{147}{ }^{148}$ In rare instances, Wernicke's encephalopathy due to vitamin $B_{1}$ deficiency has been documented. ${ }^{149}$

In view of the potential complications of severe nausea and vomiting, early diagnosis and management is important. This is of particular importance for the elite athlete in training. If a woman has nausea or vomiting of sufficient severity to affect fluid and food intake, the clinician should monitor her weight, examine for signs of dehydration (eg, tachycardia and postural hypotension), test the urine for ketones and consider assessing for signs of hypokalaemia, hypercalcaemia, hypocalcaemia or thyrotoxicosis. Early ultrasonography to identify predisposing factors should be considered (eg, multiple or molar pregnancy). ${ }^{150}$

Psychological, non-drug-based and drug-based treatments are available for women with nausea and vomiting in pregnancy and hyperemesis gravidarum. ${ }^{135}$ Dietary support and adequate fluid intake are central to management. Data suggest that women with a high intake of fatty foods have a higher risk of hyperemesis gravidarum and that low-energy high-protein diets are associated with a reduction of nausea and vomiting in pregnancy, compared with a diet high in carbohydrates. ${ }^{151}$ Women may also benefit from frequent small meals and separating wet from dry intake.

A list of possible antiemetics is given below, for when required. Availability will depend on jurisdiction. Elite athletes should ensure that any drug management is carried out in association with the Governing Body Medical Officer, to prevent using substances that are on the WADA list of banned substances (box 1).

Quality rating: high in the general pregnant population, no studies on elite athletes.

If pregnant women fail to respond or weight loss becomes significant, then early admission to the hospital is required for appropriate management.
Box 1 Drugs used commonly in obstetric practice to

treat nausea if indicated. These medications were not on the WADA list through 31 December 2015, but elite athletes should always have prescriptions coordinated by their team clinician.

Doxylamine $10 \mathrm{mg} /$ pyridoxine $10 \mathrm{mg}$ orally, three times daily with higher dose at night.

- Cyclizine $50 \mathrm{mg}$ orally, intramuscularly or intravenously, three times daily.

- Metoclopramide $10 \mathrm{mg}$ orally, intramuscularly or intravenously, three times daily.

- Prochlorperazine $5 \mathrm{mg}$ orally, $12.5 \mathrm{mg}$ intramuscularly or intravenously, three times daily; $25 \mathrm{mg}$ rectally, followed if necessary $6 \mathrm{~h}$ later by an oral dose

- Promethazine $25 \mathrm{mg}$ orally, at night

- Ondansetron 4-8 mg orally, intramuscularly, or by slow intravenous infusion, two to three times daily

Nausea and vomiting during pregnancy are common and distressing problems that can compromise quality of life, psychological well-being and performance in elite athletes who otherwise may be competing at that point in the pregnancy. ${ }^{135}$ The majority experience significant improvement by the early second trimester and can then gradually return to their usual training schedule.

\section{Fatigue}

\section{Definition}

Fatigue is 'an overwhelming sustained sense of exhaustion and decreased capacity for physical and mental work ${ }^{152}$

\section{Prevalence}

Fatigue is a common complaint throughout pregnancy and during the postpartum period, affecting approximately $90 \%$ of pregnancies. ${ }^{153}$ Factors that contribute to fatigue include living environment, support systems, employment status, socioeconomic status, age, number of children, hours of sleep, exercise and lifestyle. ${ }^{152}{ }^{154}$ The human body can adapt to fatigue, but sustained fatigue can lead to alterations in quality of life and health status. ${ }^{153}$ No studies were found to evaluate the rate of fatigue in elite athletes.

Although the majority of fatigue during pregnancy is not related to a pathological process, it is prudent to exclude severe anaemia or hypothyroidism in those with persistent symptoms. Women are considered anaemic in pregnancy if their haemoglobin in the first trimester is $<11.0$ or $<10.5 \mathrm{~g} / \mathrm{dL}$ after 28 weeks of gestation. ${ }^{150}$

Neither in the general pregnant population nor in elite athletes were clinical trials found on the effect of exercise to reduce fatigue.

\section{Mental health and well-being}

Mental health describes both positive psychosocial well-being and indicators of poor health such as mood disorders, depression and anxiety. Conditions such as eating disorders (anorexia nervosa, bulimia, female triad) are not included in this section, but athletes with these conditions need close follow-up during pregnancy. Poor maternal mental health is associated with poorer pregnancy and birth outcomes, and also poses risks for the offspring later in life. 


\section{Depression}

Depression is a state of low mood and aversion to activity that can affect a person's thoughts, behaviour, feelings and sense of well-being. ${ }^{155}$ A clinical diagnosis of depression is based on a diagnostic interview; otherwise the term 'depressive symptoms' is used. ${ }^{155}$

People with depressed mood can feel sad, anxious, empty, hopeless, helpless, worthless, guilty, irritable, ashamed or restless. They may lose interest in activities that were once pleasurable; experience overeating or loss of appetite; have problems concentrating, remembering details or making decisions; and may contemplate, attempt or commit suicide. Insomnia, excessive sleeping, fatigue, aches, pains, digestive problems or reduced energy may also be present.

In the general population, about $6.7 \%$ people suffer from depression in a 12 -month period, ${ }^{156}$ and the prevalence is higher in young adults. In pregnancy, the average prevalence of depressive symptoms over seven studies was 22.6\%. ${ }^{157} 158$

Because higher levels of physical activity and exercise are generally associated with lower risk of depressive symptoms, ${ }^{159} 160$ it is often presumed that elite athletes will suffer from depressive symptoms less frequently. However, prevalence in elite athletes would suggest no difference in rates of depression from the general population. ${ }^{161}$ As in the general population, the prevalence of depression is higher in female athletes than in male athletes. Athlete-specific triggers for depression are injury, ${ }^{162}$ failure in sport performance ${ }^{163}$ and involuntary termination of the athletic career. ${ }^{164}$ Among athletes, sports governing bodies and officials, there seems to be a tendency to downplay or ignore psychiatric problems, ${ }^{165}$ and athletes tend to under-report depressive symptoms and rarely seek help. ${ }^{161} 166167$ Whether this tendency persists in pregnancy is unknown. There are no data on the prevalence of depression among pregnant athletes.

Several studies have shown that depression during pregnancy is associated with an increased risk for poor birth outcomes, including PTB, LBW, IUGR and pre-eclampsia. ${ }^{168}$ In a meta-analysis of results from studies that used a categorical depression measure, pooled effect sizes were significantly larger (PTB: pooled risk ratio (RR $(95 \% \mathrm{CI})=1.39$ (1.19 to 1.61$)$, LBW: 1.49 (1.25 to 1.77) and IUGR: 1.45 (1.05 to 2.02)) than in studies that used a continuous depression measure (1.03 (1.00 to 1.06), 1.04 (0.99 to 1.09 ) and 1.02 (1.00 to 1.04 ), respectively). ${ }^{169} 170$ Note that even with these significant relative risks, the majority of women with mental health issues have completely normal pregnancy outcomes. Increased levels of internalising and externalising psychopathology in the children ${ }^{171}$ as well as difficulties in family relationships ${ }^{172}$ have been reported.

\section{Anxiety}

Anxiety is an emotion characterised by an unpleasant state of inner turmoil, often accompanied by nervous behaviour, such as pacing back and forth, somatic complaints and rumination. ${ }^{173}$ Anxiety is not the same as fear, which is a response to a real or perceived immediate threat, but is the expectation of future threat. ${ }^{155}$ Anxiety is often accompanied by muscular tension, restlessness, fatigue and problems in concentration.

In the general population in the Netherlands, the 12-month prevalence of anxiety disorders among women was $12.5 \%$ compared with $7.7 \%$ in men. ${ }^{174}$ High levels of anxiety are reported by around one-quarter of women in the first and second trimesters of pregnancy. ${ }^{175}$ However, no consensus exists on diagnostic instruments or cut points for identifying individuals with high anxiety levels, so prevalence rates vary between studies. No data are available for pregnant athletes, and there are limited data on anxiety in non-pregnant athletes. In Australia, one study has reported that $12 \%$ of female athletes had high anxiety scores. ${ }^{176}$

Women may also suffer from specific pregnancy-related anxiety, such as fear of having a handicapped child, fear of giving birth, and anxiety about their own changing body and appearance. ${ }^{177}$ These pregnancy-related anxieties are not associated with general anxiety or depressive feelings, ${ }^{177}$ and are reported by $14.4 \%$ of pregnant women. ${ }^{178}$ Fear of giving birth has been reported by $8 \%$ of women in a general pregnant population. ${ }^{179}$ Whether athletes suffer more or less from pregnancy-related anxieties is unknown, but they might have anxieties about being able to return to their sporting career, in the same way as some women have anxiety about returning to work. $^{180}$

\section{Prevention and treatment of depression and anxiety during} pregnancy

Pharmaceutical treatment of depressive symptoms with antidepressants, such as selective serotonin reuptake inhibitors, is common in the general population. The decision to use antidepressants in pregnancy is based on the mental health needs of the mother during pregnancy and the postpartum period balanced against any theoretic concern for the fetus. That being said, most antidepressants are not contraindicated in pregnancy. ${ }^{181}$ Any medication used by an elite athlete should fit within the WADA guidelines. ${ }^{182}$

Cognitive behavioural therapy, an effective preventive and treatment option for both depression and anxiety outside pregnancy, ${ }^{183}{ }^{184}$ is also effective in pregnancy and the postpartum period. ${ }^{185}$ A 2014 systematic review and meta-analysis found some evidence to support the effectiveness of exercise in the prevention and treatment of depression in pregnancy, based on the findings of six intervention studies of 'low-moderate' quality. ${ }^{186}$ However, these studies were not undertaken in elite athletes.

\section{Gestational weight gain}

Pre-term birth-defined as the amount of weight gained from conception to delivery-when extreme, may affect the health and well-being of the mother and infant, 89187 particularly in the second and third trimester, GWG is an important determinant of fetal growth. ${ }^{89}$ Pregnant women who gain little weight and who are below IOM recommendations, are more likely to give birth to a SGAS infant, especially normal weight and underweight women. ${ }^{187}{ }^{188}$ In addition, low GWG is associated with PTB and failure to initiate breast feeding. ${ }^{188} 189$ On the other hand, women who gain above the recommended amount have increased risk of GDM and hypertensive disorders, prolonged labour, caesarean section, macrosomia and large for gestational age infants, as well as postpartum weight retention and later overweight/ obesity. ${ }^{190-192}$ Both GWG above and below recommendations could occur in elite athletes, and may be of concern for pregnancy outcomes as well as for return to sport.

Current recommendations for GWG were issued in $2009^{89}$ and are based on pre-pregnancy BMI categories (table 2). Women pregnant with twins are given separate 
recommendations, ranging from 16.8 to $24.5 \mathrm{~kg}$ (37-54 lbs) for normal weight women, 14.1 to $22.7 \mathrm{~kg}$ (31-50 lbs) for overweight women and 11.3 to $19.1 \mathrm{~kg}(25-42 \mathrm{lbs})$ for obese women. There are no recommendations specifically for elite athletes.

\section{Description of GWG}

GWG is derived from both maternal and fetoplacental factors, including increased blood volume (3-4 lbs or $1.4-1.8 \mathrm{~kg}$ ), uterus ( $2 \mathrm{lbs}$ or $0.9 \mathrm{~kg}$ ), increased extracellular fluid (3-4 lbs or $1.4-1.8 \mathrm{~kg}$ ), larger breasts (1-2 lbs or $0.4-0.9 \mathrm{~kg}$ ), fat stores for breast feeding (5-8 lbs or $2.3-3.6 \mathrm{~kg}$ ), the baby (7-8 lbs or $3-3.6 \mathrm{~kg})$, placenta $(1-1.5 \mathrm{lbs}$ or $0.5-0.7 \mathrm{~kg})$ and amniotic fluid (2 lbs or $0.9-1 \mathrm{~kg}) .{ }^{88} 89$

The rate of weight gain is usually lowest $(0.5-2.0 \mathrm{~kg}$ in total) in the first trimester, highest in the second trimester (on average below $0.50 \mathrm{~kg} /$ week) and relatively constant or somewhat decreasing towards the end of the third trimester. ${ }^{88} 89$

\section{Adherence to weight gain recommendations}

Recent data from the USA show that approximately 15-20\% of women gained below, 26-36\% gained within and $42-57 \%$ gained above the IOM recommendations relating to GWG. ${ }^{193-197}$ Hence, in a high percentage of pregnant women, weight gain is outside the current guidelines.

\section{The role of exercise and GWG}

In the general obstetric population, observational studies have shown inconsistent results with respect to relationships between exercise/physical activity and GWG. Some studies have shown that a decline in exercise from pre-pregnancy levels was significantly related to higher GWG. ${ }^{119}{ }^{198}$ Another longitudinal cohort study showed that women meeting the physical activity guidelines ( $\geq 30 \mathrm{~min}$ per day) had $29 \%$ (95\% CI $0.57 \%$ to $0.88 \%$ ) lower odds of gaining above the IOM recommendations than did inactive women. ${ }^{199}$ Stuebe et $a l^{200} 201$ also reported that mid-pregnancy walking and moderate-intensity exercise, in accordance with present guidelines, was inversely associated with the risk of excessive GWG.

Of potential relevance for athletes, studies have shown that exercise performance influences neither the rate of early pregnancy weight gain nor subcutaneous fat deposition (skinfold thickness), with both decreasing in late pregnancy. Still, overall pregnancy weight gain was within the normal range. ${ }^{202-204}$ Also, higher pre-pregnancy physical activity levels have been associated with less GWG, ${ }^{205}$ which is relevant for the athlete. Only one observational study reporting GWG in elite athletes was found. ${ }^{206}$ In this retrospective study of 40 Norwegian elite athletes and age-matched controls with normal pre-pregnancy BMI, self-reported mean GWG was lower in the athletes than in the controls $(13.9 \mathrm{SD} 6.9 \mathrm{~kg}$ vs17.5 SD $9.1 \mathrm{~kg}, \mathrm{p}=0.06$ ).

\section{Prevention and treatment}

Several randomised controlled trials (RCTs) have investigated the effect of exercise on GWG and results differ. ${ }^{8}{ }^{207-230}$ However, none of these RCTs included competitive athletes. $\mathrm{Kardel}^{91}$ investigated the effect of a high-volume and mediumvolume training regime in pregnant elite athletes $(n=41)$, and in neither fat percentage nor GWG was a significant difference between the two training groups reported. Studies investigating the impact of training volume on GWG throughout pregnancy (early vs late) and the effect on the growing fetus are warranted, but difficult to conduct. Quality rating: low, no RCTs in elite athletes. As long as symphysis fundal heights are consistent with gestational age, more frequent ultrasound assessments are not required for elite athletes.

\section{Pre-eclampsia}

\section{Definition}

Pre-eclampsia represents a spectrum of hypertensive disorders complicated by proteinuria presenting exclusively during pregnancy. The spectrum includes those who develop minor versions of the disorder near term as well as those who develop severe versions that require significantly premature delivery, the only known cure for the disorder. In addition to hypertension and proteinuria, the most severely affected patients may also develop evidence of end-organ effects manifested by haemolysis, abnormal liver or renal function, clotting disorders, and thrombocytopaenia. Severe cases may also present with fetal growth restriction, increasing the risk of stillbirth. ${ }^{231}$ A detailed expert review on pre-eclampsia was published by Stocks. ${ }^{232}$ The level of the quality of the body of evidence for this topic is moderate.

\section{Prevalence}

Pre-eclampsia affects between $2 \%$ and $7 \%$ of women having their first child and, of these, $75 \%$ will present with signs and symptoms near term. ${ }^{231}$ Multiparous women have a lower risk of pre-eclampsia at $1.7 \% .^{233}$ Compared with Caucasian women, African, African-American and Latina women have an increased risk of pre-eclampsia. ${ }^{234} 235$ The overall rate of pre-eclampsia has been rising over the past 20 years, due to an increase in two common risk factors, obesity and diabetes. ${ }^{236}$ There are no studies on prevalence of this condition in elite athletes.

\section{Risk factors}

The cause and exact mechanisms for pre-eclampsia remain unclear, but several risk factors have been identified (table 1). Lack of physical activity should be added to this list. Some of these risk factors would generally be considered to be less prevalent in the elite athlete population than in the general population due to their tendency to younger age and low rates of obesity (box 2).

\section{Box 2 Risk factors for pre-eclampsia}

Nulliparity

- Pre-eclampsia in a previous pregnancy

- Maternal age $>40$ years

- Assisted reproductive technologies

- Obesity or excessive weight gain in pregnancy

- Mother or sister with history of pre-eclampsia

- Maternal low birth weight or premature delivery

- Heritable thrombophilias

- Chronic hypertension

- Type 1 diabetes mellitus

- Renal disease

- Multifetal gestation

- Cocaine or amphetamine use

- (references: 231 and 237) 


\section{Box 3 Diagnosis}

Pre-eclampsia is diagnosed by the combination of new hypertension $>140 / 90 \mathrm{~mm} \mathrm{Hg}$ and proteinuria after 20 weeks of gestation. Proteinuria should be suspected when there is a urinary dipstick of $>1+$. This should be quantified using either a $24 \mathrm{~h}$ urine protein collection of $>0.3 \mathrm{~g} /$ day, or spot urinary albumin of $>30 \mathrm{mg} / \mathrm{mmol}$ of creatinine. Pre-eclampsia is considered severe if any of the following are present: systolic blood pressure $>160 \mathrm{~mm} \mathrm{Hg}$, diastolic blood pressure $>110 \mathrm{~mm} \mathrm{Hg}$, severe headache or visual disturbances, right upper quadrant/epigastric pain, nausea and vomiting, proteinuria $>5 \mathrm{~g} /$ day, oliguria $<500 \mathrm{~mL} / 24 \mathrm{~h}$, pulmonary oedema or fetal growth restriction. 231237

Once pre-eclampsia is diagnosed (box 3), most patients will undergo investigations to determine whether there have been associated end-organ effects. The typical investigations include a blood smear, haemoglobin and haematocrit count, platelet count, liver transaminases, creatinine, uric acid, and clotting studies. By performing these investigations, care givers can exclude the HELLP (haemolysis, elevated liver enzymes, low platelets) syndrome, one of the most severe versions of preeclampsia. In addition, evaluation of the fetus is required to assess growth and well-being.

\section{Treatment}

There is no specific treatment for pre-eclampsia. Management will depend on the severity of hypertension, evidence of end-organ effects, assessments of fetal well-being and, most importantly, gestational age. Most commonly, induction of labour will be offered to term patients with mild pre-eclampsia, whereas, the same patient, when at less than 34 weeks of gestation, may be placed on antihypertensives and given corticosteroids to advance fetal lung maturity, with an attempt to achieve a greater gestational age at birth. In contrast, despite even a gestational age $<28$ weeks, patients with the most severe forms of pre-eclampsia will require early delivery as there is no other cure for the rapidly worsening hypertension and end-organ effects. The most severely affected patients will also be treated with magnesium sulfate before and after delivery, to prevent the development of seizures (eclampsia). ${ }^{231} 237$

\section{Mechanisms through which exercise might reduce the risk of pre-eclampsia}

Weissgerber $e t$ al $^{238}$ proposed four mechanisms by which exercise might reduce the rate of pre-eclampsia. These include enhanced placental growth and vascularity; prevention and/or reduction of oxidative stress; reduction of inflammation; and correction of endothelial dysfunction. Each of these potentially interactive factors promotes endothelial dysfunction, which leads to late stage symptoms of pre-eclampsia. ${ }^{236} 239$ They also suggest that, for maximum effect on these mechanisms, exercise should be started in the first trimester. ${ }^{236} 238$

\section{The role of exercise in preventing pre-eclampsia}

Most studies evaluating the effect of exercise on the rate of preeclampsia demonstrate benefit. In their 2014 meta-analysis, ${ }^{233}$ Wolf $e t \mathrm{al}^{233}$ included 11 observational studies evaluating the impact of leisure time physical activity on the rate of preeclampsia. No RCTs were included. The amount of physical activity was self-reported in all studies and included leisure activities such as gardening, walking, running and other aerobic exercises.

When evaluating the impact of strenuous exercise during pregnancy on the rate of pre-eclampsia, the studies were inconsistent, with four showing a reduction in pre-eclampsia and the others showing no benefit. One study identified an increased risk of severe pre-eclampsia in those who exercised more than $270 \mathrm{~min} /$ week. None of the studies showed any benefit of light or moderate leisure time physical activity on the rate of pre-eclampsia. ${ }^{233}$

Also, in 2014, Aune et $a^{234}$ published their systematic review and meta-analysis of data from 15 cohort and case-control studies. They reported a $40 \%$ reduction in pre-eclampsia for those women who performed strenuous exercise prior to pregnancy, but with no further improvement with durations $>5-6 \mathrm{~h}$ of exercise per week. For studies that reported exercise before 24 weeks gestation, they identified a $21 \%$ reduction in preeclampsia, with greater benefit in those who exercised at high intensity ( $45 \%$ reduction) than in those who exercised at low intensity. Compared with non-exercisers, women who exercised before and during pregnancy had a 36\% reduction in pre-eclampsia. ${ }^{234}$

Only one small RCT has evaluated exercise and risk of preeclampsia. ${ }^{240}$ There was a significantly lower rate of preeclampsia in the stretching exercise group $(2.6 \%, \mathrm{~N}=38)$ than in the walking group $(14.6 \%, \mathrm{~N}=41)$. The authors also identified a significantly higher rate of transferrin, an antioxidant marker, in the stretching group, and suggested that regular stretching produces more endogenous antioxidants. Quality rating: low. No studies have evaluated the effects of exercise on the rate of pre-eclampsia in elite athletes.

\section{Gestational hypertension}

Gestational hypertension is newfound hypertension $>140 / 90$ after 20 weeks gestation without proteinuria. ${ }^{231}$

\section{Prevalence}

Approximately $6 \%$ of women will develop gestational hypertension and $25 \%$ of these will go on to develop pre-eclampsia, which is discussed in another section of this document. ${ }^{231} 241$ There are no studies in elite athletes.

\section{Risk factors}

Risk factors for gestational hypertension include nulliparity, advanced maternal age, obesity, diabetes and renal disease. $^{242} 243$

\section{Diagnosis}

Gestational hypertension is diagnosed after 20 weeks gestation in women with no history of hypertension and no proteinuria when the blood pressure is $>140 / 90$ on at least two occasions, at least $4 \mathrm{~h}$ apart. ${ }^{231}$

\section{Treatment}

Treatment of gestational hypertension is dependent on gestational age. Given the frequency that gestational hypertension transitions to pre-eclampsia, most women at term will be offered induction of labour to avoid the possibility of this more serious hypertensive complication of pregnancy. Women who are preterm are commonly started on antihypertensive medications and the frequency of assessments is increased to look for evidence of pre-eclampsia, or fetal growth restriction. ${ }^{231}$ 
The role of exercise in the prevention of gestational hypertension The large majority of studies evaluating the impact of exercise on hypertensive complications of pregnancy have used the rate of pre-eclampsia, rather than the milder gestational hypertension, as the outcome.

Two epidemiological studies have evaluated the impact of exercise exposure before and during pregnancy on the rate of gestational hypertension. One reported a $70 \%$ reduction in gestational hypertension among Hispanic women who exercised before pregnancy; however, the upper confidence limit was 1.0. ${ }^{244}$ The other found no effect of exercise before or during pregnancy on the rate of gestational hypertension. ${ }^{245}$ However, a recent large RCT showed that women who initiate structured exercise early in pregnancy are three times more likely to prevent gestational hypertension, are 1.5 times more likely to prevent excessive GWG and are 2.5 times more likely to prevent macrosomic or large babies. ${ }^{246}$ Quality rating for prevention: moderate, no studies in elite athletes.

To date, no study has evaluated exercise as a therapy for gestational hypertension (quality rating: very low) and no studies of gestational hypertension have been conducted with elite athletes.

\section{Oedema}

Oedema refers to the accumulation of excessive watery fluid in cells, tissues, or serous cavitites. It is very common for pregnant women to experience dependent oedema, especially during the third trimester. It is also linked to pre-eclampsia and hypertension. The physiological explanation for dependent oedema is related to the substantial increase in blood volume, vessel permeability and extracellular fluids, as well as the obstructive pressure of the uterus on the vena cava. There are no published studies suggesting prenatal exercise as a cause of dependent oedema.

Hydrotherapy has been suggested as a treatment for dependent oedema by increasing hydrostatic pressure and causing diuresis. ${ }^{247}$ Kent $e t a l^{248}$ investigated the impact of hydrotherapy on dependent oedema. Eighteen healthy women between 20 and 33 weeks were evaluated for 30 min segments standing on land, standing in water to the axilla and during a low-intensity water aerobics class with water to the axilla on separate days and in a random order. Diuresis posttherapy was higher for water aerobics $(187 \mathrm{~mL})$ and static immersion $(180 \mathrm{~mL})$ than for standing on land $(65 \mathrm{~mL}, \mathrm{p}=0.01)$. Hartmann and $\mathrm{Huch}^{249}$ also showed that a single session of immersion exercise significantly decreased the volume and circumference of both legs. Level of evidence: low. No studies in elite athletes.

\section{Gestational diabetes \\ Definition}

GDM is glucose intolerance with onset or first recognition during pregnancy.

\section{Prevalence}

The prevalence of GDM is increasing, affecting almost $10 \%$ of pregnancies, a reflection of the global obesity epidemic. ${ }^{250} 251$ Women diagnosed with GDM are at high risk for future diabetes, with approximately $50 \%$ of women developing type 2 diabetes within 5 years of delivery. It has been estimated that, in some populations, women with a history of GDM may account for up to one-third of diabetes cases among parous women. ${ }^{252}$ Women with GDM represent a heterogeneous group. Some women have unrecognised pre-existing type 2 diabetes and a small number have type 1 diabetes, with onset during pregnancy; however, the majority are first diagnosed during pregnancy. $^{250}$

There are no prevalence studies of GDM among elite athletes. However, women who are most active before 253254 and during pregnancy $^{255}$ are at lower risk of developing GDM. ${ }^{256} 257$

\section{Pathophysiology}

During pregnancy, insulin resistance increases and euglycaemia is maintained through a compensatory increase in insulin secretion. GDM appears to be a failure to compensate with increased insulin secretion. As the increase in insulin resistance is greatest in the third trimester, GDM usually develops during this time. Therefore, screening for GDM typically occurs around 24-28 weeks gestation. $^{258} 259$

\section{Diagnosis of GDM}

There has been much debate about which-universal or selective-screening of pregnant women for GDM is more appropriate. Selective screening for those with the highest risk has been recommended, especially in low-risk countries. As the prevalence of GDM increases, there is a tendency towards universal screening, as $40 \%$ of GDM cases remain undiagnosed using selective screening. ${ }^{260} 261$ The fasted oral glucose tolerance test is the diagnostic test, although criteria vary around the world.

Risk factors for the development of GDM include obesity, older age, family history, previous history of GDM, or poor obstetric outcomes, ethnicity, polycystic ovarian syndrome and, as recently noted, hypertension. ${ }^{250} 258$ Lack of physical activity before and during pregnancy may lead to obesity and is an important risk factor. ${ }^{262-267}$

GDM is strongly associated with adverse prenatal and postnatal outcomes, and is related to long-term and short-term morbidity in both the offspring and mother. Adverse infant outcomes include macrosomia (babies born $>4.0 \mathrm{~kg}$ ), hypoglycaemia, erythaema, hypocalcaemia, jaundice and birth trauma. ${ }^{250268}$ Later in life, these children are more likely to become obese, have abnormal glucose tolerance and to develop diabetes in adolescence or early adulthood. Women with GDM experience an increased risk of developing pre-eclampsia, infection and postpartum haemorrhage, and are more likely to develop overt diabetes, usually type 2, after pregnancy. ${ }^{250} 251$

Given the risk factors, high-level exercisers and elite athletes would be expected to have reduced risk for developing GDM. ${ }^{269}$ Therefore, we do not review intervention studies in this report.

\section{Musculoskeletal complaints \\ Pelvic girdle pain and low back pain \\ Definition}

Pelvic girdle pain (PGP) is pain experienced between the posterior iliac crest and the gluteal fold, particularly in the vicinity of the sacroiliac joints. ${ }^{270}$

PGP often arises in relation to pregnancy, with pain related to the pelvic musculoskeletal system and not from gynaecological or urological disorders. After the exclusion of lumbar causes, diagnosis of PGP can be made by reproducing the pain/functional impairments related to PGP, using specific clinical tests. ${ }^{270}$

Although similar and overlapping features may be ascribed to low back pain (LBP) and to PGP, during pregnancy, PGP appears to have more impact on disability than does LBP. ${ }^{38} 270-273$ PGP disorders have a characteristic clinical presentation, and with this comes a need for specific management. ${ }^{273-275}$ Pregnancy-related LBP and PGP are common in many countries, 
regardless of socioeconomic factors, ${ }^{276-278}$ and have a negative effect on daily activities, exercise and training. ${ }^{279}$

\section{Prevalence}

The prevalence rate of pregnancy-related LBP and PGP is estimated to be about $50 \%$ during pregnancy. ${ }^{280}$ An estimated $20-25 \%$ of all pregnant women suffer from PGP sufficiently seriously to require medical help. ${ }^{270} 280$ Only one study has investigated PGP and LBP in elite athletes, reporting a prevalence of $29.6 \%$ for PGP and $18.5 \%$ for LBP during pregnancy, similar to non-athletic controls. ${ }^{206}$ Previous LBP, previous LBP and/or PGP during or after pregnancy, strenuous work and previous trauma to the pelvis, are commonly identified risk factors. ${ }^{270} 280$

\section{Aetiology and pathogenesis}

The aetiology and pathogenesis of PGP is uncertain and probably multifactorial. The pelvis transfers load from the trunk to the legs and this requires a stable pelvis. Overload of the ligaments of the pelvis may be a result of impaired load transfer during activities and hence have an influence on PGP. ${ }^{281-283}$ The sacrospinous and the long dorsal sacroiliac ligament are both thought to be a possible source of pain in PGP. ${ }^{284-288}$ The changes in spinal curvature during pregnancy as well as frequent or sustained pain-provoking postures might influence the pelvic ligaments, causing pain. It is probably important that elite athletes are aware of their body positions while pregnant to avoid unnecessary load and stress on joint, ligaments and muscles, during exercise and daily activities.

\section{Treatment and prevention}

Twenty-six RCTs that examined the effects of a variety of interventions for LBP and PGP during pregnancy were included in an updated Cochrane review. ${ }^{289}$ Based on evidence of moderate quality, this review suggests that different types of exercise and acupuncture significantly reduce evening PGP or lumbopelvic pain more than normal care alone. According to the European guideline for PGP, individualised exercises to treat PGP in pregnancy are recommended. ${ }^{270}$

There is limited knowledge on how to prevent LBP and PGP in pregnancy, ${ }^{289}$ with lack of evidence of a positive effect of group training, ${ }^{290-293}$ and inconsistent findings on whether regular physical activity before pregnancy can reduce the risk of LBP and/or PGP during pregnancy. ${ }^{294} 295$ Women who reported high-impact exercise 3-5 times per week before pregnancy had a $14 \%$ lower risk of developing severe PGP in pregnancy compared with non-exercisers. ${ }^{296}$ In a longitudinal cohort study, a greater loss of physical condition seems not to be a cause but rather a consequence of LBP and/or PGP in pregnancy, ${ }^{297}$ hence knowledge about type of exercise and dose is needed. Quality rating: moderate. No studies on prevention or treatment of LBP and PGP in pregnant elite athletes were identified.

\section{Pelvic floor dysfunction}

\section{Definitions}

Pelvic floor dysfunction (PFD) is defined as the presence of symptoms of UI or AI, POP, sensory or emptying abnormalities of the lower urinary tract, defaecation dysfunction, sexual dysfunction and pelvic floor pain syndromes. The conditions can present separately or coexist. ${ }^{298}$ UI is defined as a complaint of involuntary passing of urine. ${ }^{299}$ The most prevalent form of female PFD is stress UI (SUI) - 'the complaint of involuntary leakage on effort or exertion (eg, sporting activities), or on sneezing or coughing, ${ }^{299}$ Urgency UI (UUI) is the complaint of involuntary passing of urine associated with urgency. ${ }^{299} \mathrm{AI}$ is 'involuntary passing of faeces or flatus', while faecal incontinence is limited to involuntary passing of faeces (solid or liquid). ${ }^{299}$ The definition of anatomical POP is 'the descent of one or more of the anterior vaginal wall, posterior vaginal wall, the uterus (cervix), or the apex of the vagina (vaginal vault or cuff scar after hysterectomy)'. ${ }^{299}$ The presence of any such sign should be correlated with relevant POP symptoms. POP ranges from asymptomatic minor changes in vaginal support, common after childbirth, to severe vaginal bulging for which women choose treatment.

\section{Prevalence}

The prevalence of UI in nulliparous women and in female elite athletes is high. ${ }^{300} 301$ Prevalence rates range between $28 \%$ and $80 \%$ during sporting activities in female elite athletes. ${ }^{301}$ UI occurs most commonly in sports involving high-impact activities such as trampolining and gymnastics. While athletes report that they feel embarrassed about the condition and that it may affect performance, in one study, $84 \%$ had never spoken with their coaches or healthcare providers about UI. ${ }^{302}$ In a retrospective study on Norwegian elite athletes who had given birth, $12.9 \%$ reported SUI the year before the birth and $18.5 \%$ during pregnancy. These rates of prevalence did not differ from those in a matched control group. ${ }^{206}$

AI affects one in four primiparous women during the third trimester. $^{303} 304$ In one study, the prevalence of AI, generally limited to flatus incontinence, was higher in women (aged $18-40$ years) who exercised more than $8 \mathrm{~h} /$ week $(14.8 \%)$ than in a comparison group $(4.9 \%, \mathrm{p}=0.001) .{ }^{305}$ In the retrospective study of elite athletes, none recalled AI during pregnancy or after childbirth. ${ }^{206}$

Among 116 nulliparous female US Military Academy cadets, those who attended paratrooper training were significantly more likely to demonstrate stage II POP on examination after 6 weeks than those who did not $(\mathrm{RR}=2.72, \quad 1.37<\mathrm{RR}<5.40$; $\mathrm{p}=0.003) .^{306}$

No prospective studies of POP in elite female athletes (pregnant or non-pregnant) were found.

\section{Aetiology and risk factors for PFDs}

Risk factors for PFDs include pregnancy and childbirth-related factors (injuries to peripheral nerves, connective tissue and muscles), heritage and ethnicity, obesity, behavioural factors, ageing, and strenuous work. Vaginal birth is the strongest risk factor for POP in women of all ages, while vaginal birth increases the risk for UI by about two-fold in younger and middle-aged women, but no longer plays a role in older women. ${ }^{123} 300307$

DeLancey et $a l^{308}$ presented an integrated life span model of causal factors of PFD. Phase I comprises predisposing factors, which include genetic construction, nutritional factors and socialisation. Phase II comprises inciting factors, which include predisposing maternal-fetal factors such as pelvic floor shape and size, macrosomic infant, fetal head position, effects of obstetric interventions such as use of forceps, prolonged second stage and occipit posterior position, all leading to potential injury (muscle, connective tissue and nerve avulsion/compression). Phase III comprises intervening factors, which include variation in normal ageing of muscles, nerves and connective tissue; increased stress to the pelvic floor (occupational lifting, strenuous activity, obesity or chronic cough); and factors leading to weakening of the support tissues (chronic steroid use or disuse atrophy of muscles). 
Aetiology and risk factors for $\mathrm{UI}$ in elite athletes

$\mathrm{B} \varnothing$ et $a l^{301}$ found that women exercising $\geq 3$ times per week at gestational week 37 had a significantly larger levator hiatus area than did non-exercising women. However, these women were not elite athletes. In a study of college athletes, Nygaard et al ${ }^{309}$ found no significant association between UI and amenorrhoea, weight, hormonal therapy or duration of athletic activity. In a study of former US Olympians, among factors such as age, BMI, parity, Olympic sport group and incontinence during Olympic sport 20 years ago, only current BMI was significantly associated with regular SUI or urgency incontinence symptoms. ${ }^{310} \mathrm{~B} \varnothing$ and Sundgot-Borgen ${ }^{311}$ reported that significantly more elite athletes with eating disorders had symptoms of both SUI and UUI. Eliasson et $\mathrm{al}^{312}$ showed that incontinent trampolinists were significantly older (16 vs 13 years), had been training longer and more frequently, and were less able to interrupt the urine flow stream by voluntarily contracting the pelvic floor muscle, than the non-leaking group.

\section{Prevention and treatment}

Devices that involve external urinary collection, intravaginal support of the bladder neck or blockage of urinary leakage by occlusion are available, ${ }^{313}$ and some have reportedly been effective in preventing leakage during physical activity. ${ }^{314}$ For smaller leakage, specially designed protecting pads can be used during training and competition. No RCTs have evaluated the effect of preventive devices in elite athletes.

According to the most recent Cochrane review, in the general population, pregnant women without UI randomly assigned to intensive antenatal pelvic floor muscle training were less likely to report UI up to 6 months after delivery than were controls who received usual care (about 30\% less; RR 0.71, 95\% CI 0.54 to 0.95 , combined result of five trials). ${ }^{315}$ As several studies have found that $>30 \%$ of women are not able to perform a correct PFM contraction at their first consultation, thorough instruction of how to perform a contraction and assessment of ability to contract is vital. ${ }^{316}$ In studies with favourable results, the women have performed supervised PFM training in combination with home exercise. 315

\section{Prevention/treatment}

No studies were found on prevention or treatment strategies for diastasis recti abdominis during pregnancy, either in the general pregnant population or in elite athletes. Quality rating: high in the general population. There are no studies of interventions to prevent or reduce PFD during pregnancy in female elite athletes.

\section{Diastasis recti abdominis \\ Definition}

Diastasis recti abdominis (DRA) is an impairment with midline separation of the two rectus abdominis muscles along the linea alba. $^{317}$

\section{Prevalence}

Prevalence rates (with and without protrusion/hernia) during pregnancy vary between $27 \%$ and $100 \%$ in the second and third trimester. ${ }^{318} 319$ There are no prevalence studies among elite athletes during pregnancy.

DRA is diagnosed by measuring the distance between the median borders of rectus abdominis (inter-rectus distance); measurement methods in use are palpation with fingerbreadths, caliper or ultrasound. ${ }^{320}$ To date, there is no consensus on where to measure the distance along the linea alba, or on the cut-point for diagnosing the condition. ${ }^{319}$

\section{Aetiology and risk factors}

The aetiology of DRA is not clear. While some believe that DRA affects abdominal muscle strength or spinal stability during pregnancy, we identified no data on DRA and LBP or PGP during pregnancy, and found no studies testing the theory that DRA can be prevented or treated with abdominal or other exercises during pregnancy. A recently published systematic review concluded that there is an urgent need for more research on the prevalence, risk factors, prevention and treatment of the condition. ${ }^{321}$ Female athletes usually train the abdominals regularly and anecdotally have stronger abdominal muscles than the general population. Whether this is a protective factor or a risk factor for development of DRA in pregnancy is not known. Quality rating: very low. There is no evidence to guide elite athletes on abdominal training during pregnancy.

\section{Other parts in the 5-part series}

In addition to this Part 1, four other parts of IOC expert group meeting will be published in future issues of BJSM.

Part 2: Effect of having exercised (physical fitness) on labour and neonatal/fetal outcomes.

Part 3: Guidance on returning to exercise in the the postpartum period.

Part 4: Research directions.

Part 5: Recommendations for health professionals and active women.

\section{Author affiliations}

${ }^{1}$ Norwegian School of Sport Sciences, Oslo, Norway

${ }^{2}$ Department of Obstetrics/Gynecology and Women's Health, Saint Louis University, St Louis, Missouri, USA

${ }^{3}$ Facultad de Ciencias de la Actividad Física y del Deporte — INEF, Universidad

Politécnica de Madrid, Madrid, Spain

${ }^{4}$ Centre for Research on Exercise, School of Human Movement and Nutrition

Sciences, University of Queensland, St Lucia, Queensland, Australia

${ }^{5}$ Department of Maternal-Fetal Medicine, Queens University, Kingston, Ontario,

Canada

${ }^{6}$ The Poundbury Clinic Dorchester-The Poundbury Suite, King Edward VII Hospital London, London, UK

${ }^{7}$ University of North Carolina at Chapel Hill, Chapel Hill, North Carolina, USA

${ }^{8}$ Department of Epidemiology, Gillings School of Global Public Health, Chapel Hill,

North Carolina, USA

${ }^{9}$ Department of Sport Sciences, Norwegian School of Sport Sciences, Oslo, Norway

${ }^{10}$ The Swedish School of Sport and Health Sciences, Stockholm, Sweden

${ }^{11}$ Faculty of Biology and Medicine, Institute of Sports Science, University of Lausanne, Lausanne, Switzerland

${ }^{12}$ University Lecturer, School of Health Sciences, University of Tampere, Tampere, Finland

${ }^{13}$ Department of Children, Young People and Families, The National Institute for Health and Welfare, Helsinki, Finland

${ }^{14} \mathrm{R}$ Samuel McLaughlin Foundation-Exercise and Pregnancy Lab, The University of Western Ontario London, London, Ontario, Canada

${ }^{15}$ Department of Obstetrics and Gynecology, University of Utah, Salt Lake City, Utah, USA

${ }^{16}$ Institute of Sport Science, University of Graz, Graz, Austria

${ }^{17}$ Oslo University Hospital, Ullevål, Oslo, Norway

${ }^{18}$ Department of Family Practice \& Centre for Hip Health and Mobility, University of British Columbia, Vancouver, British Columbia, Canada

Contributors $\mathrm{KB}$ conceived the idea and consulted all the other authors in the development of the consensus meeting. All the authors prepared material and submitted it in advance of the in person meeting in Lausanne. All the authors contributed materially to drafting the various versions of the document and approved the final version.

Funding IOC, 10.13039/501100003965, Internal Funds For Consensus Meetings. Competing interests None declared.

Provenance and peer review Not commissioned; internally peer reviewed. 


\section{REFERENCES}

1 [No authors listed]. Committee Opinion No. 650 Summary: physical activity and exercise during pregnancy and the postpartum period. Obstet Gynecol 2015;126:1326-7.

2 Davies GA, Wolfe LA, Mottola MF, et al. Exercise in pregnancy and the postpartum period. J Obstet Gynaecol Can 2003;25:516-29.

3 Royal College of Obstetricians and Gynaecologists. Exercise in pregnancy 2006:1-7.

4 Evenson KR, Mottola MF, Owe KM, et al. Summary of international guidelines for physical activity after pregnancy. Obstet Gyneco/ Surv 2014;69:407-14.

5 Evenson KR, Barakat R, Brown WJ, et al. Guidelines for physical activity during pregnancy: comparisons from around the world. Am J Lifestyle Med 2014;8:102-21.

6 Szumilewicz A, Worska A, Rajkowska N, et al. Summary of guidelines for exercise in pregnancy-are they comprehensive enough for designing the contents of a prenatal exercise program? Curr Womens Health Rev 2015;11:3-12.

7 Owe KM, Nystad W, Skjaerven R, et al. Exercise during pregnancy and the gestational age distribution: a cohort study. Med Sci Sports Exerc 2012:44:1067-74.

8 Haakstad LA, Bo K. Exercise in pregnant women and birth weight: a randomized controlled trial. BMC Pregnancy Childbirth 2011;11:66.

9 Gjestland K, Bo K, Owe KM, et al. Do pregnant women follow exercise guidelines? Prevalence data among 3482 women, and prediction of low-back pain, pelvic girdle pain and depression. Br J Sports Med 2013;47:515-20.

10 Engebretsen L, Bahr R, Cook JL, et al. The IOC Centres of Excellence bring prevention to sports medicine. Br J Sports Med 2014;48:1270-5.

11 Higgins JPT, Green S. Cochrane handbook for systematic reviews of interventions. John Wiley \& Sons, 2008.

12 Bouchard C, Shephard S. Physical activity, fitness, and health: the model and key concepts. In: Bouchard C, Shephard R, Stephens T, eds. Physical activity, fitness and health International proceedings and consensus statement. Champaign, IL: Human Kinetics Publishers, 1993:11-23.

13 American College of Obstetricians and Gynecologists. ACOG Committee Opinion number 313, September 2005. The importance of preconception care in the continuum of women's health care. Obstet Gynecol Surv 2005;106:665-6.

14 Lu MC, Kotelchuck M, Culhane JF, et al. Preconception care between pregnancies: the content of internatal care. Matern Child Health J 2006;10 Suppl):S107-22.

15 Dunson DB, Colombo B, Baird DD. Changes with age in the level and duration of fertility in the menstrual cycle. Hum Reprod 2002;17:1399-403.

16 Jamieson ME, Coutts JR, Connor JM. The chromosome constitution of human preimplantation embryos fertilized in vitro. Hum Reprod 1994;9:709-15.

17 Habbema JD, Eijkemans MJ, Leridon $\mathrm{H}$, et al. Realizing a desired family size: when should couples start? Hum Reprod 2015;30:2215-21.

18 Mountjoy M, Sundgot-Borgen J, Burke L, et al. The IOC consensus statement: beyond the Female Athlete Triad-Relative Energy Deficiency in Sport (RED-S). Br J Sports Med 2014;48:491-7.

19 Mountjoy M, Sundgot-Borgen J, Burke L, et al. Authors' 2015 additions to the IOC consensus statement: Relative Energy Deficiency in Sport (RED-S). Br J Sports Med 2015;49:417-20.

20 Mountjoy M, Sundgot-Borgen J, Burke L, et al. The IOC relative energy deficiency in sport clinical assessment tool (RED-S CAT). Br J Sports Med 2015;49:1354.

21 Mountjoy M, Sundgot-Borgen J, Burke L, et al. RED-S CAT. Relative Energy Deficiency in Sport (RED-S) Clinical Assessment Tool (CAT). Br J Sports Med 2015;49:421-3

22 Currie A. Sport and eating disorders-understanding and managing the risks Asian J Sports Med 2010;1:63-8.

23 Czech-Szczapa B, Szczapa T, Merritt TA, et al. Disordered eating attitudes during pregnancy in mothers of newborns requiring Neonatal Intensive Care Unit admission: a case control study. J Matern Fetal Neonatal Med 2015;28:1711-15.

24 Sundgot-Borgen J, Torstveit MK. Prevalence of eating disorders in elite athletes is higher than in the general population. Clin J Sport Med 2004;14:25-32.

25 Sundgot-Borgen J, Torstveit MK. Aspects of disordered eating continuum in elite high-intensity sports. Scand J Med Sci Sports 2010;20(Suppl 2):112-21.

26 Nielsen S, Moller-Madsen S, Isager T, et al. Standardized mortality in eating disorders - a quantitative summary of previously published and new evidence. J Psychosom Res 1998;44:413-34.

27 Cardwell MS. Eating disorders during pregnancy. Obstet Gynecol Surv 2013;68:312-23.

28 Franko DL, Spurrell EB. Detection and management of eating disorders during pregnancy. Obstet Gynecol 2000;95(Pt 1):942-6.

29 Mazzeo SE, Slof-Op't Landt MC, Jones I, et al. Associations among postpartum depression, eating disorders, and perfectionism in a population-based sample of adult women. Int J Eat Disord 2006;39:202-11.

30 Koubaa S, Hallstrom T, Lindholm C, et al. Pregnancy and neonatal outcomes in women with eating disorders. Obstet Gynecol 2005;105:255-60.

31 Park RJ, Senior R, Stein A. The offspring of mothers with eating disorders. Eur Child Adolesc Psychiatry 2003;12(Suppl 1):1110-19.
32 Patel P, Wheatcroft R, Park RJ, et al. The children of mothers with eating disorders. Clin Child Fam Psychol Rev 2002;5:1-19.

33 James DC. Eating disorders, fertility, and pregnancy: relationships and complications. J Perinat Neonatal Nurs 2001;15:36-48; quiz 2 p following 82.

34 Franko DL, Blais MA, Becker AE, et al. Pregnancy complications and neonatal outcomes in women with eating disorders. Am J Psychiatry 2001;158:1461-6

35 Mottola M. Performance in the pregnant woman: maternal and foetal considerations. In: Taylor N, Groeller H, eds. Physiological bases of human performance during work and exercise. Elsevier, 2008:225-37.

36 Barakat R, Perales M, Garatachea N, et al. Exercise during pregnancy. A narrative review asking: what do we know? Br J Sports Med 2015;49:1377-81.

37 Hartmann S, Bung P. Physical exercise during pregnancy-physiological considerations and recommendations. J Perinat Med 1999;27:204-15.

38 Ostgaard HC, Andersson GB, Schultz AB, et al. Influence of some biomechanical factors on low-back pain in pregnancy. Spine 1993;18:61-5.

39 Hagan L, Wong C. Gait in pregnant women: spinal and lower extremity changes from pre- to Postpartum. J Womens Health Phys Ther 2010;34:46-56.

40 Branco M, Santos-Rocha R, Aguiar L, et al. Kinematic analysis of gait in the second and third trimesters of pregnancy. J Pregnancy 2013;2013:718095.

41 Carpes F, Griebeler D, Kleinpaul J, et al. Women able-bodied gait kinematics during and post pregnancy period. Rev Bras Biomeĉanica 2008;9:16.

42 Gilleard WL. Trunk motion and gait characteristics of pregnant women when walking: report of a longitudinal study with a control group. BMC Pregnancy Childbirth 2013;13:71.

43 Forczek W, Staszkiewicz R. Changes of kinematic gait parameters due to pregnancy. Acta Bioeng Biomech 2012;14:113-9.

44 Foti T, Davids JR, Bagley A. A biomechanical analysis of gait during pregnancy. J Bone Joint Surg Am 2000;82:625-32.

45 Lymbery JK, Gilleard W. The stance phase of walking during late pregnancy: temporospatial and ground reaction force variables. J Am Podiatr Med Assoc 2005:95:247-53.

46 Lontay B, Bodoor K, Sipos A, et al. Pregnancy and Smoothelin-like Protein 1 (SMTNL 1) deletion promote the switching of skeletal muscle to a glycolytic phenotype in human and mice. J Biol Chem 2015;290:17985-98.

47 Cakmak B, Ribeiro AP, Inanir A. Postural balance and the risk of falling during pregnancy. J Matern Fetal Neonatal Med 2016;29:1623-5.

48 Vladutiu CJ, Evenson KR, Marshall SW. Physical activity and injuries during pregnancy. J Phys Act Health 2010;7:761-9.

49 Norwitz ER, Schust DJ, Fisher SJ. Implantation and the survival of early pregnancy. N Engl J Med 2001;345:1400-8.

50 Weissgerber TL, Wolfe LA. Physiological adaptation in early human pregnancy: adaptation to balance maternal-fetal demands. Appl Physiol Nutr Metab 2006:31:1-11.

51 Duvekot JJ, Cheriex EC, Pieters FA, et al. Early pregnancy changes in hemodynamics and volume homeostasis are consecutive adjustments triggered by a primary fall in systemic vascular tone. Am J Obstet Gynecol 1993;169: 1382-92.

52 Morris EA, Hale SA, Badger GJ, et al. Pregnancy induces persistent changes in vascular compliance in primiparous women. Am J Obstet Gynecol 2015;212:633. e1-6.

53 Pivarnik J. Cardiovascular responses to aerobic exercise during pregnancy and postpartum. Sem Perinatol 1996;20:242-9.

54 Cong J, Fan T, Yang $X$, et al. Structural and functional changes in maternal left ventricle during pregnancy: a three-dimensional speckle-tracking echocardiography study. Cardiovasc Ultrasound 2015;13:6.

55 Rubler S, Damani PM, Pinto ER. Cardiac size and performance during pregnancy estimated with echocardiography. Am J Cardiol 1977;40:534-40.

56 Hart MA. Nursing implications of self-care in pregnancy. MCN Am J Matern Child Nurs 1996;21:137-43.

57 Wolfe LA, Preston RJ, Burggraf GW, et al. Effects of pregnancy and chronic exercise on maternal cardiac structure and function. Can J Physiol Pharmacol 1999;77:909-17.

58 Wolfe LA, Ohtake PJ, Mottola MF, et al. Physiological interactions between pregnancy and aerobic exercise. Exerc Sport Sci Rev 1989;17:295-351.

59 Pivarnik JM, Lee W, Miller JF, et al. Alterations in plasma volume and protein during cycle exercise throughout pregnancy. Med Sci Sports Exerc 1990;22:751-5.

60 Pivarnik JM, Mauer MB, Ayres NA, et al. Effects of chronic exercise on blood volume expansion and hematologic indices during pregnancy. Obstet Gynecol 1994;83:265-9.

61 Gilson GJ, Samaan S, Crawford MH, et al. Changes in hemodynamics, ventricular remodeling, and ventricular contractility during normal pregnancy: a longitudinal study. Obstet Gynecol 1997;89:957-62.

62 Wolfe LA, Weissgerber TL. Clinical physiology of exercise in pregnancy: a literature review. J Obstet Gynaecol Can 2003;25:473-83.

63 Ratigan TR. Anatomic and physiologic changes of pregnancy: anesthetic considerations. AANA J 1983;51:38-42. 
64 Weissgerber TL, Wolfe LA, Hopkins WG, et al. Serial respiratory adaptations and an alternate hypothesis of respiratory control in human pregnancy. Respir Physiol Neurobiol 2006;153:39-53.

65 Heenan AP, Wolfe LA. Plasma acid-base regulation above and below ventilatory threshold in late gestation. J Appl Physiol 2000;88:149-57.

66 Wolfe LA, Kemp JG, Heenan AP, et al. Acid-base regulation and control of ventilation in human pregnancy. Can J Physiol Pharmacol 1998;76:815-27.

67 Milne JA, Howie AD, Pack Al. Dyspnoea during normal pregnancy. Br J Obstet Gynaecol 1978;85:260-3.

68 Field SK, Bell SG, Cenaiko DF, et al. Relationship between inspiratory effort and breathlessness in pregnancy. J App/ Physiol 1991;71:1897-902.

69 Jensen D, Webb KA, Wolfe LA, et al. Effects of human pregnancy and advancing gestation on respiratory discomfort during exercise. Respir Physiol Neurobiol 2007; 156:85-93.

70 Ibrahim S, Jarefors E, Nel DG, et al. Effect of maternal position and uterine activity on periodic maternal heart rate changes before elective cesarean section at term. Acta Obstet Gynecol Scand 2015;94:1359-66.

71 Avery ND, Stocking KD, Tranmer JE, et al. Fetal responses to maternal strength conditioning exercises in late gestation. Can J Appl Physiol 1999;24:362-76.

72 Jeffreys RM, Stepanchak W, Lopez B, et al. Uterine blood flow during supine rest and exercise after 28 weeks of gestation. Br J Obstet Gyneacol

2006;113:1239-47.

73 Bauer MK, Harding JE, Bassett NS, et al. Fetal growth and placental function. Mol Cell Endocrinol 1998;140:115-20.

74 Mottola MF, Christopher PD. Effects of maternal exercise on liver and skeletal muscle glycogen storage in pregnant rats. J App/ Physiol 1991;71:1015-19.

75 Catalano PM, Tyzbir ED, Roman NM, et al. Longitudinal changes in insulin release and insulin resistance in nonobese pregnant women. Am J Obstet Gynecol 1991;165(Pt 1):1667-72

76 Buchanan TA, Metzger BE, Freinkel N, et al. Insulin sensitivity and B-cell responsiveness to glucose during late pregnancy in lean and moderately obese women with normal glucose tolerance or mild gestational diabetes. Am J Obstet Gynecol 1990;162:1008-14.

77 Lesser KB, Carpenter MW. Metabolic changes associated with normal pregnancy and pregnancy complicated by diabetes mellitus. Semin Perinatol 1994;18:399-406

78 Clapp JF III. Maternal carbohydrate intake and pregnancy outcome. Proc Nutr Soc 2002;61:45-50

79 Butte NF. Carbohydrate and lipid metabolism in pregnancy: normal compared with gestational diabetes mellitus. Am J Clin Nutr 2000;71(5 Suppl):1256S-61S.

80 Boden $\mathrm{G}$. Fuel metabolism in pregnancy and in gestational diabetes mellitus. Obstet Gynecol Clin North Am 1996;23:1-10.

81 Bessinger RC, McMurray RG. Substrate utilization and hormonal responses to exercise in pregnancy. Clin Obstet Gynecol 2003;46:467-78.

82 Chambers CD. Risks of hyperthermia associated with hot tub or spa use by pregnant women. Birth Defects Res A Clin Mol Teratol 2006;76:569-73.

83 Soultanakis HN, Artal R, Wiswell RA. Prolonged exercise in pregnancy: glucose homeostasis, ventilatory and cardiovascular responses. Semin Perinatol 1996;20:315-27

84 Clapp JF III. The changing thermal response to endurance exercise during pregnancy. Am J Obstet Gynecol 1991;165(Pt 1):1684-9.

85 Lindqvist PG, Marsal K, Merlo J, et al. Thermal response to submaximal exercise before, during and after pregnancy: a longitudinal study. J Matern Fetal Neonatal Med 2003;13:152-6.

86 Jones RL, Botti JJ, Anderson WM, et al. Thermoregulation during aerobic exercise in pregnancy. Obstet Gynecol 1985;65:340-5.

87 Hytten F. Weight gain in pregnancy. In: Hytten F, Chamberlain G, eds. Clinical physiology in obstetrics. Oxford: Blackwell Scientific Publications, 1991:173-203.

88 Butte NF, King JC. Energy requirements during pregnancy and lactation. Public Health Nutr 2005;8:1010-27.

89 IOM (Institute of Medicine) and NRC (National Research Council). Weight gain during pregnancy: reexamining the guidelines. Washington DC: The National Academies Press, 2009.

90 Clapp JF III, Capeless E. The V02max of recreational athletes before and after pregnancy. Med Sci Sports Exerc 1991;23:1128-33.

91 Kardel KR. Effects of intense training during and after pregnancy in top-level athletes. Scand J Med Sci Sports 2005;15:79-86.

92 Wolfe LA, Brenner IK, Mottola MF. Maternal exercise, fetal well-being and pregnancy outcome. Exerc Sport Sci Rev 1994;22:145-94.

93 Kennelly MM, Geary M, McCaffrey N, et al. Exercise-related changes in umbilical and uterine artery waveforms as assessed by Doppler ultrasound scans. Am J Obstet Gynecol 2002;187:661-6.

94 Kennelly MM, McCaffrey N, McLoughlin P, et al. Fetal heart rate response to strenuous maternal exercise: not a predictor of fetal distress. Am J Obstet Gynecol 2002;187:811-16

95 van Doorn MB, Lotgering FK, Struijk PC, et al. Maternal and fetal cardiovascular responses to strenuous bicycle exercise. Am J Obstet Gynecol 1992;166:854-9.
96 Kardel KR, Johansen B, Voldner N, et al. Association between aerobic fitness in late pregnancy and duration of labor in nulliparous women. Acta Obstet Gynecol Scand 2009;88:948-52.

97 MacPhail A, Davies GA, Victory R, et al. Maximal exercise testing in late gestation: fetal responses. Obstet Gynecol 2000;96:565-70.

98 Heenan AP, Wolfe LA, Davies GA. Maximal exercise testing in late gestation: maternal responses. Obstet Gynecol 2001;97:127-34.

99 Jaque-Fortunato SV, Wiswell RA, Khodiguian N, et al. A comparison of the ventilatory responses to exercise in pregnant, postpartum, and nonpregnant women. Semin Perinatol 1996;20:263-76.

100 Mottola MF, Davenport MH, Brun CR, et al. V02peak prediction and exercise prescription for pregnant women. Med Sci Sports Exerc 2006;38:1389-95.

101 Salvesen KA, Hem E, Sundgot-Borgen J. Fetal wellbeing may be compromised during strenuous exercise among pregnant elite athletes. Br J Sports Med 2012;46:279-83.

102 Szymanski LM, Satin AJ. Strenuous exercise during pregnancy: is there a limit? Am J Obstet Gynecol 2012;207:179.e1-6.

103 Szymanski LM, Satin AJ. Exercise during pregnancy: fetal responses to current public health guidelines. Obstet Gynecol 2012;119:603-10.

104 Dibblee L, Graham TE. A longitudinal study of changes in aerobic fitness, body composition, and energy intake in primigravid patients. Am J Obstet Gynecol 1983;147:908-14.

105 Wong SC, McKenzie DC. Cardiorespiratory fitness during pregnancy and its effect on outcome. Int J Sports Med 1987;8:79-83.

106 Pivarnik JM, Lee W, Miller JF. Physiological and perceptual responses to cycle and treadmill exercise during pregnancy. Med Sci Sports Exerc 1991;23:470-5.

107 Carey DG, Tofte C, Pliego GJ, et al. Transferability of running and cycling training zones in triathletes: implications for steady-state exercise. I Strength Cond Res 2009;23:251-8.

108 Artal $R$, Wiswell $R$, Romem $Y$, et al. Pulmonary responses to exercise in pregnancy. Am J Obstet Gynecol 1986;154:378-83.

109 McMurray RG, Katz VL, Berry MJ, et al. The effect of pregnancy on metabolic responses during rest, immersion, and aerobic exercise in the water. Am J Obstet Gynecol 1988;158(Pt 1):481-6.

110 Knuttgen HG, Emerson K Jr. Physiological response to pregnancy at rest and during exercise. J Appl Physiol 1974;36:549-53.

111 O'Neill ME, Cooper KA, Mills CM, et al. Accuracy of Borg's ratings of perceived exertion in the prediction of heart rates during pregnancy. Br J Sports Med 1992;26:121-4.

112 Tenforde AS, Toth $\mathrm{KE}$, Langen $\mathrm{E}$, et al. Running habits of competitive runners during pregnancy and breastfeeding. Sports health 2015;7:172-6.

113 Sandbakk Ø, Hegge A, Losnegard T, et al. The physiological capacity of the world's highest ranked female cross-country skiers. Med Sci Sports 2016. Published Online First.

114 Huch R. Physical activity at altitude in pregnancy. Semin Perinatol 1996;20:303-14.

115 Artal R, Fortunato V, Welton A, et al. A comparison of cardiopulmonary adaptations to exercise in pregnancy at sea level and altitude. Am J Obstet Gynecol 1995;172(Pt 1):1170-8; discussion 78-80

116 Entin PL, Coffin L. Physiological basis for recommendations regarding exercise during pregnancy at high altitude. High Alt Med Biol 2004;5:321-34.

117 Clapp JF III. Is exercise during pregnancy related to preterm birth? Clin J Sport Med 2009;19:241-3.

118 Clapp JF III. Exercise during pregnancy. A clinical update. Clin Sports Med 2000;19:273-86.

119 Olson D, Sikka RS, Hayman J, et al. Exercise in pregnancy. Curr Sports Med Rep 2009;8:147-53.

120 O'Connor PJ, Poudevigne MS, Cress ME, et al. Safety and efficacy of supervised strength training adopted in pregnancy. J Phys Act Health 2011;8:309-20.

121 Palatini $\mathrm{P}, \mathrm{Mos} \mathrm{L}$, Munari L, et al. Blood pressure changes during heavy-resistance exercise. J Hypertens Supp/ 1989;7:S72-3.

122 Harman EA, Frykman PN, Clagett ER, et al. Intra-abdominal and intra-thoracic pressures during lifting and jumping. Med Sci Sports Exerc 1988;20:195-201.

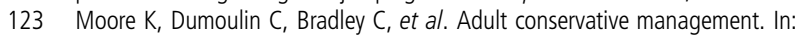
Abrams P, Cardozo L, Khoury S, eds. Abrams P, Cardozo L, Khoury S, Wein A. Incontinence. 5th edn. Committee 12 International Consultation on Incontinence, 2013:1101-227

124 Dumas GA, Reid JG. Laxity of knee cruciate ligaments during pregnancy. J Orthop Sports Phys Ther 1997;26:2-6

125 Aitokallio-Tallberg A, Halmesmaki E. Motor vehicle accident during the second or third trimester of pregnancy. Acta Obstet Gynecol Scand 1997;76:313-17.

126 Luley T, Fitzpatrick CB, Grotegut CA, et al. Perinatal implications of motor vehicle accident trauma during pregnancy: identifying populations at risk. Am J Obstet Gynecol 2013;208:466.e1-5.

127 Vladutiu CJ, Marshall SW, Poole C, et al. Adverse pregnancy outcomes following motor vehicle crashes. Am J Prev Med 2013;45:629-36.

128 Baud D, Damnon F, de Rham M. Should a pregnancy test be required before scuba diving? Br J Sports Med 2016:(in press) File number 095770.

129 Camporesi EM. Diving and pregnancy. Semin Perinatol 1996;20:292-302. 
130 Zhou Q, O'Brien B, Soeken K. Rhodes Index of Nausea and Vomiting--Form 2 in pregnant women. A confirmatory factor analysis. Nurs Res 2001;50:251-7.

131 Lacasse A, Rey E, Ferreira $E$, et al. Nausea and vomiting of pregnancy: what about quality of life? Br J Obstet Gyneacol 2008;115:1484-93.

132 Jewell D. Nausea and vomiting in early pregnancy. Clin Evid 2003(9):1561-70.

133 Jewell $D$, Young $G$. Interventions for nausea and vomiting in early pregnancy. Cochrane Database Syst Rev 2003;(4):CD000145.

134 Miller F. Nausea and vomiting in pregnancy: the problem of perception-is it really a disease? Am J Obstet Gynecol 2002;186(5 Suppl Understanding):S182-3.

135 Jarvis S, Nelson-Piercy C. Management of nausea and vomiting in pregnancy. BMJ 2011;342:d3606.

136 Woodhouse M. Complementary medicine for pregnancy complications Australian Family Physician 2007:35(9):695. Aus Fam Phys 2007;35:695.

137 Einarson TR, Piwko C, Koren G. Prevalence of nausea and vomiting of pregnancy in the USA: a meta analysis. J Popul Ther Clin Pharmacol 2013:20:e163-70.

138 Goodwin TM. Nausea and vomiting of pregnancy: an obstetric syndrome. Am J Obstet Gynecol 2002;186(5 Suppl Understanding):S184-9.

139 Buckwalter JG, Simpson SW. Psychological factors in the etiology and treatment of severe nausea and vomiting in pregnancy. Am J Obstet Gynecol 2002;186(5 Suppl Understanding):S210-14.

140 Chan RL, Olshan AF, Savitz DA, et al. Maternal influences on nausea and vomiting in early pregnancy. Matern Child Health J 2011;15:122-7.

141 O'Brien B, Relyea MJ. Use of indigenous explanations and remedies to further understand nausea and vomiting during pregnancy. Health Care Women Int 1999;20:49-61

142 Tan PC, Vani S, Lim BK, et al. Anxiety and depression in hyperemesis gravidarum: prevalence, risk factors and correlation with clinical severity. Eur J Obstet Gynecol Reprod Biol 2010:149:153-8.

143 Chou FH, Avant KC, Kuo SH, et al. Relationships between nausea and vomiting, perceived stress, social support, pregnancy planning, and psychosocial adaptation in a sample of mothers: a questionnaire survey. Int I Nurs Stud 2008:45:1185-91.

144 Chou FH, Kuo SH, Wang RH. A longitudinal study of nausea and vomiting, fatigue and perceived stress in, and social support for, pregnant women through the three trimesters. Kaohsiung J Med Sci 2008;24:306-14.

145 Mansour GM, Nashaat EH. Role of Helicobacter pylori in the pathogenesis of hyperemesis gravidarum. Arch Gynecol Obstet 2011;284:843-7.

146 Sandven I, Abdelnoor M, Wethe M, et al. Helicobacter pylori infection and Hyperemesis gravidarum. An institution-based case-control study. Eur I Epidemiol 2008:23:491-8

147 Fejzo MS, Poursharif B, Korst LM, et al. Symptoms and pregnancy outcomes associated with extreme weight loss among women with hyperemesis gravidarum. J Womens Health (Larchmt) 2009:18:1981-7.

148 van Oppenraaij RH, Jauniaux E, Christiansen OB, et al. Predicting adverse obstetric outcome after early pregnancy events and complications: a review. Hum Reprod Update 2009;15:409-21.

149 Chiossi G, Neri I, Cavazzuti M, et al. Hyperemesis gravidarum complicated by Wernicke encephalopathy: background, case report, and review of the literature. Obstet Gynecol Surv 2006:61:255-68.

150 NICE (National Institute for Health \& Care Excellence). Antenatal care for uncomplicated pregnancies, 2014. www.nice.org.uk/guidelines

151 Jednak MA, Shadigian EM, Kim MS, et al. Protein meals reduce nausea and gastric slow wave dysrhythmic activity in first trimester pregnancy. Am J Physiol 1999;277(Pt 1):G855-61.

152 Pugh LC. Childbirth and the measurement of fatigue. J Nurs Meas 1993;1:57-66.

153 Bialobok KM, Monga M. Fatigue and work in pregnancy. Curr Opin Obstet Gynecol 2000;12:497-500.

154 van Lier D, Manteuffel B, Dilorio C, et al. Nausea and fatigue during early pregnancy. Birth 1993;20:193-7.

155 American Psychiatric Association. Diagnostic and Statistical Manual of Mental Disorders (DSM-5). Arlington, VA: American Psychiatric Pub, 2013.

156 Murphy S. Transitions in competitive sport: maximizing individual potential. In: Murphy SM, ed. Sport psychology interventions. Champaign, IL: Human Kinetics, 1995:331-46.

157 Molyneaux E, Poston L, Ashurst-Williams S, et al. Pre-pregnancy obesity and mental disorders during pregnancy and postpartum: a systematic review and meta-analysis. Pregnancy Hypertens 2014;4:236

158 Molyneaux E, Poston L, Ashurst-Williams S, et al. Obesity and mental disorders during pregnancy and postpartum: a systematic review and meta-analysis. Obstet Gynecol 2014;123:857-67.

159 Loprinzi PD, Cardinal BJ. Interrelationships among physical activity, depression, homocysteine, and metabolic syndrome with special considerations by sex. Prev Med 2012:54:388-92.

160 Loprinzi PD, Fitzgerald EM, Cardinal BJ. Physical activity and depression symptoms among pregnant women from The National Health and Nutrition Examination Survey 2005-2006. J Obstet Gynecol Neonatal Nurs 2012;41:227-35.

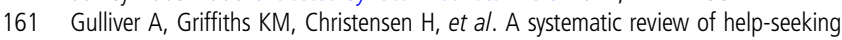
interventions for depression, anxiety and general psychological distress. BMC Psychiatry 2012;12:81.
162 Appaneal RN, Levine BR, Perna FM, et al. Measuring postinjury depression among male and female competitive athletes. J Sport Exerc Psychol 2009;31:60-76.

163 Hammond T, Gialloreto C, Kubas $\mathrm{H}$, et al. The prevalence of failure-based depression among elite athletes. Clin I Sport Med 2013:23:273-7.

164 Wolanin A, Gross M, Hong E. Depression in athletes: prevalence and risk factors. Curr Sports Med Rep 2015;14:56-60.

165 Reardon CL, Factor RM. Sport psychiatry: a systematic review of diagnosis and medical treatment of mental illness in athletes. Sports Med 2010:40:961-80.

166 Gulliver A, Griffiths KM, Christensen H. Barriers and facilitators to mental health help-seeking for young elite athletes: a qualitative study. BMC Psychiatry 2012;12:157.

167 Schwenk TL. The stigmatisation and denial of mental illness in athletes. Br J Sports Med 2000:34:4-5.

168 Kim DR, Sockol LE, Sammel MD, et al. Elevated risk of adverse obstetric outcomes in pregnant women with depression. Arch Womens Ment Health 2013;16:475-82.

169 Grote V, Vik T, von Kries $R$, et al. Maternal postnatal depression and child growth: a European cohort study. BMC Pediatr 2010;10:14.

170 Grote NK, Bridge JA, Gavin AR, et al. A meta-analysis of depression during pregnancy and the risk of preterm birth, low birth weight, and intrauterine growth restriction. Arch Gen Psychiatry 2010;67:1012-24.

171 Brennan PA, Hammen C, Andersen MJ, et al. Chronicity, severity, and timing of maternal depressive symptoms: relationships with child outcomes at age 5. Dev Psychol 2000;36:759-66.

172 Garber J. Depression and the family. In: Hudson J, Rapee R, eds. Psychopathology and the family. Oxford: Elsevier, 2005:27-83.

173 Seligman M, Walker E, Rosenhan D. Abnormal psychology. 4th edn. New York: W.W. Norton \& Company, 2000

174 de Graaf R, ten Have M, van Gool C, et al. Prevalence of mental disorders and trends from 1996 to 2009. Results from the Netherlands Mental Health Survey and Incidence Study-2. Soc Psychiatry Psychiatr Epidemiol 2012;47:203-13.

175 Claesson IM, Josefsson A, Sydsjo G. Prevalence of anxiety and depressive symptoms among obese pregnant and postpartum women: an intervention study. BMC Public Health 2010;10:766.

176 Gulliver A, Griffiths KM, Mackinnon A, et al. The mental health of Australian elite athletes. J Sci Med Sport 2015;18:255-61.

177 Huizink AC, Mulder EJ, Robles de Medina PG, et al. Is pregnancy anxiety a distinctive syndrome? Early Hum Dev 2004;79:81-91.

178 Poikkeus P, Saisto T, Unkila-Kallio L, et al. Fear of childbirth and pregnancy-related anxiety in women conceiving with assisted reproduction. Obstet Gynecol 2006;108:70-6

179 Storksen HT, Garthus-Niegel S, Adams SS, et al. Fear of childbirth and elective caesarean section: a population-based study. BMC Pregnancy Childbirth 2015:15:221.

180 Kaitz M. Maternal concerns during early parenthood. Child Care Health Dev 2007:33:720-7.

181 Weisskopf E, Fischer CJ, Bickle Graz M, et al. Risk-benefit balance assessment of SSRI antidepressant use during pregnancy and lactation based on best available evidence. Expert Opin Drug Saf 2015;14:413-27.

182 Vernec AR. The Athlete Biological Passport: an integral element of innovative strategies in antidoping. Br J Sports Med 2014;48:817-19.

183 Hofmann SG, Smits JA. Cognitive-behavioral therapy for adult anxiety disorders: a meta-analysis of randomized placebo-controlled trials. J Clin Psychiatry 2008;69:621-32.

184 Newby JM, McKinnon A, Kuyken W, et al. Systematic review and meta-analysis of transdiagnostic psychological treatments for anxiety and depressive disorders in adulthood. Clin Psychol Rev 2015;40:91-110.

185 Sockol LE, Battle CL. Maternal attitudes, depression, and anxiety in pregnant and postpartum multiparous women. Arch Womens Ment Health 2015;18:585-93.

186 Daley AJ, Foster L, Long G, et al. The effectiveness of exercise for the prevention and treatment of antenatal depression: systematic review with meta-analysis. $\mathrm{Br} J$ Obstet Gyneacol 2015;122:57-62.

187 Siega-Riz AM, Viswanathan M, Moos MK, et al. A systematic review of outcomes of maternal weight gain according to the Institute of Medicine recommendations: birthweight, fetal growth, and postpartum weight retention. Am J Obstet Gynecol 2009:201:339.e1-14.

188 Viswanathan M, Siega-Riz AM, Moos MK, et al. Outcomes of maternal weight gain. Evid Rep Technol Assess (Full Rep) 2008:1-223.

189 Alavi N, Haley S, Chow K, et al. Comparison of national gestational weight gain guidelines and energy intake recommendations. Obes Rev 2013;14:68-85.

190 Artal R, Lockwood CJ, Brown HL. Weight gain recommendations in pregnancy and the obesity epidemic. Obstet Gynecol 2010;115:152-5.

191 Crane JM, White J, Murphy P, et al. The effect of gestational weight gain by body mass index on maternal and neonatal outcomes. J Obstet Gynaecol Can 2009:31:28-35

192 Macdonald-Wallis C, Tilling K, Fraser A, et al. Gestational weight gain as a risk factor for hypertensive disorders of pregnancy. Am J Obstet Gynecol 2013;209:327 e1-17. 
193 Harris DE, Aboueissa AM, Baugh N, et al. 11-year trends in pregnancy-related health indicators in Maine, 2000-2010. J Pregnancy 2014;2014:780626.

194 Johnson JL, Farr SL, Dietz PM, et al. Trends in gestational weight gain: the Pregnancy Risk Assessment Monitoring System, 2000-2009. Am J Obstet Gynecol 2015;212:806.e1-8.

195 Yan J. Maternal pre-pregnancy BMI, gestational weight gain, and infant birth weight: a within-family analysis in the United States. Econ Hum Biol 2015:18:1-12.

196 Park S, Sappenfield WM, Bish C, et al. Assessment of the Institute of Medicine recommendations for weight gain during pregnancy: Florida, 2004-2007. Matern Child Health J 2011:15:289-301.

197 Simas TA, Waring ME, Liao X, et al. Prepregnancy weight, gestational weight gain, and risk of growth affected neonates. J Womens Health (Larchmt) 2012;21:410-17.

198 Merkx A, Ausems M, Bude L, et al. Weight gain in healthy pregnant women in relation to pre-pregnancy BMI, diet and physical activity. Midwifery 2015:31:693-701.

199 Kraschnewski JL, Chuang CH, Downs DS, et al. Association of prenatal physical activity and gestational weight gain: results from the first baby study. Womens Health Issues 2013;23:e233-8.

200 Stuebe AM, Forman MR, Michels KB. Maternal-recalled gestational weight gain pre-pregnancy body mass index, and obesity in the daughter. Int I Obes (Lond) 2009;33:743-52.

201 Stuebe AM, Oken E, Gillman MW. Associations of diet and physical activity during pregnancy with risk for excessive gestational weight gain. Am J Obstet Gynecol 2009:201:58.e1-8.

202 Clapp JF, Little KD. The interaction between regular exercise and selected aspects of women's health. Am J Obstet Gynecol 1995:173:2-9.

203 Clapp JF III, Little KD. Effect of recreational exercise on pregnancy weight gain and subcutaneous fat deposition. Med Sci Sports Exerc 1995;27:170-7.

204 Jiang H, Qian X, Li M, et al. Can physical activity reduce excessive gestational weight gain? Findings from a Chinese urban pregnant women cohort study. Int $J$ Behav Nutr Phys Act 2012;9:12.

205 Lof M, Hilakivi-Clarke L, Sandin S, et al. Effects of pre-pregnancy physical activity and maternal BMI on gestational weight gain and birth weight. Acta Obstet Gynecol Scand 2008;87:524-30.

206 Bo K, Backe-Hansen KL. Do elite athletes experience low back, pelvic girdle and pelvic floor complaints during and after pregnancy? Scand I Med Sci Sports 2007:17:480-7.

207 Ruchat SM, Davenport MH, Giroux I, et al. Nutrition and exercise reduce excessive weight gain in normal-weight pregnant women. Med Sci Sports Exerc 2012:44:1419-26.

208 Vinter CA, Jorgensen JS, Ovesen P, et al. Metabolic effects of lifestyle intervention in obese pregnant women. Results from the randomized controlled trial 'Lifestyle in Pregnancy' (LiP). Diabet Med 2014;31:1323-30.

209 Renault KM, Norgaard K, Nilas L, et al. The Treatment of Obese Pregnant Women (TOP) study: a randomized controlled trial of the effect of physical activity intervention assessed by pedometer with or without dietary intervention in obese pregnant women. Am J Obstet Gynecol 2014;210: 134.e1-9.

210 Ruiz JR, Perales M, Pelaez M, et al. Supervised exercise-based intervention to prevent excessive gestational weight gain: a randomized controlled trial. Mayo Clin Proc 2013:88:1388-97.

211 Ronnberg AK, Ostlund I, Fadl $\mathrm{H}$, et al. Intervention during pregnancy to reduce excessive gestational weight gain-a randomised controlled trial. $\mathrm{Br} J$ Obstet Gyneacol 2015;122:537-44.

212 Phelan S, Phipps MG, Abrams B, et al. Randomized trial of a behavioral intervention to prevent excessive gestational weight gain: the Fit for Delivery Study. Am J Clin Nutr 2011:93:772-9.

213 Huang TT, Yeh CY, Tsai YC. A diet and physical activity intervention for preventing weight retention among Taiwanese childbearing women: a randomised controlled trial. Midwifery 2011;27:257-64.

214 Hui AL, Back L, Ludwig S, et al. Effects of lifestyle intervention on dietary intake, physical activity level, and gestational weight gain in pregnant women with different pre-pregnancy body mass index in a randomized control trial. BMC Pregnancy Childbirth 2014;14:331.

215 Bogaerts A, Van den Bergh BR, Ameye L, et al. Interpregnancy weight change and risk for adverse perinatal outcome. Obstet Gynecol 2013;122:999-1009.

216 Haakstad LA, Bo K. Effect of regular exercise on prevention of excessive weight gain in pregnancy: a randomised controlled trial. Eur I Contracept Reprod Health Care 2011:16:116-25

217 Asbee SM, Jenkins TR, Butler JR, et al. Preventing excessive weight gain during pregnancy through dietary and lifestyle counseling: a randomized controlled trial. Obstet Gynecol 2009:113(Pt 1):305-12.

218 Guelinckx I, Devlieger R, Mullie P, et al. Effect of lifestyle intervention on dietary habits, physical activity, and gestational weight gain in obese pregnant women: a randomized controlled trial. Am J Clin Nutr 2010;91:373-80.
219 Harrison CL, Lombard CB, Strauss BJ, et al. Optimizing healthy gestational weight gain in women at high risk of gestational diabetes: a randomized controlled trial. Obesity (Silver Spring) 2013;21:904-9.

220 Barakat $R$, Cordero $Y$, Coteron J, et al. Exercise during pregnancy improves maternal glucose screen at 24-28 weeks: a randomised controlled trial. Br I Sports Med 2012:46:656-61.

221 Ghodsi Z, Asltoghiri M. Effects of aerobic exercise training on maternal and neonatal outcome: a randomized controlled trial on pregnant women in Iran. J Pak Med Assoc 2014;64:1053-6.

222 Korpi-Hyovalti EA, Laaksonen DE, Schwab US, et al. Feasibility of a lifestyle intervention in early pregnancy to prevent deterioration of glucose tolerance. $B M C$ Public Health 2011;11:179.

223 Luoto $\mathrm{R}$, Laitinen $\mathrm{K}$, Nermes $\mathrm{M}$, et al. Impact of maternal probiotic-supplemented dietary counseling during pregnancy on colostrum adiponectin concentration: a prospective, randomized, placebo-controlled study. Early Hum Dev 2012;88:339-44

224 Nascimento SL, Surita FG, Parpinelli MA, et al. The effect of an antenatal physical exercise programme on maternal/perinatal outcomes and quality of life in overweight and obese pregnant women: a randomised clinical trial. Br J Obstet Gyneacol 2011;118:1455-63.

225 Price BB, Amini SB, Kappeler K. Exercise in pregnancy: effect on fitness and obstetric outcomes—a randomized trial. Med Sci Sports Exerc 2012;44:2263-9.

226 Kong KL, Campbell CG, Foster RC, et al. A pilot walking program promotes moderate-intensity physical activity during pregnancy. Med Sci Sports Exerc 2014;46:462-71.

227 Jackson RA, Stotland NE, Caughey AB, et al. Improving diet and exercise in pregnancy with Video Doctor counseling: a randomized trial. Patient Educ Couns 2011;83:203-9.

228 Kinnunen $\mathrm{Tl}$, Raitanen J, Aittasalo $\mathrm{M}$, et al. Preventing excessive gestational weight gain —a secondary analysis of a cluster-randomised controlled trial. Eur 」 Clin Nutr 2012;66:1344-50

229 Santos IA, Stein R, Fuchs SC, et al. Aerobic exercise and submaximal functional capacity in overweight pregnant women: a randomized trial. Obstet Gynecol 2005;106:243-9.

230 Hui A, Back L, Ludwig S, et al. Lifestyle intervention on diet and exercise reduced excessive gestational weight gain in pregnant women under a randomised controlled trial. Br J Obstet Gyneacol 2012;119:70-7.

231 Gabbe S, Niebyl J, Simpson J, et al. Obstetrics: normal and problem pregnancies. 6th edn. Saunders, 2012

232 Stocks G. Preeclampsia: pathophysiology, old and new strategies for management. Eur J Anaesthesiol 2014;31:183-9.

233 Wolf $\mathrm{HT}$, Owe KM, Juhl $\mathrm{M}$, et al. Leisure time physical activity and the risk of pre-eclampsia: a systematic review. Matern Child Health J 2014;18:899-910.

234 Aune D, Saugstad OD, Henriksen T, et al. Physical activity and the risk of preeclampsia: a systematic review and meta-analysis. Epidemiology 2014:25:331-43.

235 Nakimuli A, Chazara 0, Byamugisha J, et al. Pregnancy, parturition and preeclampsia in women of African ancestry. Am J Obstet Gynecol 2014;210:510-20.e1.

236 Genest DS, Falcao S, Gutkowska J, et al. Impact of exercise training on preeclampsia: potential preventive mechanisms. Hypertension 2012;60:1104-9.

237 Magee LA, Pels A, Helewa M, et al. Diagnosis, evaluation, and management of the hypertensive disorders of pregnancy: executive summary. J Obstet Gynaecol Can 2014;36:416-41.

238 Weissgerber TL, Wolfe LA, Davies GA, et al. Exercise in the prevention and treatment of maternal-fetal disease: a review of the literature. Appl Physiol Nutr Metab 2006;31:661-74.

239 Weissgerber TL, Wolfe LA, Davies GA. The role of regular physical activity in preeclampsia prevention. Med Sci Sports Exerc 2004:36:2024-31.

240 Yeo S, Davidge S, Ronis DL, et al. A comparison of walking versus stretching exercises to reduce the incidence of preeclampsia: a randomized clinical trial. Hypertens Pregnancy 2008;27:113-30

241 Walker RL, Hemmelgarn B, Quan H. Incidence of gestational hypertension in the Calgary Health Region from 1995 to 2004. Can J Cardiol 2009;25:e284-7.

242 Ros HS, Cnattingius S, Lipworth L. Comparison of risk factors for preeclampsia and gestational hypertension in a population-based cohort study. Am J Epidemiol 1998;147:1062-70.

243 Shiozaki A, Matsuda Y, Satoh S, et al. Comparison of risk factors for gestational hypertension and preeclampsia in Japanese singleton pregnancies. J Obstet Gynaecol Res 2013:39:492-9.

244 Fortner RT, Pekow PS, Whitcomb BW, et al. Physical activity and hypertensive disorders of pregnancy among Hispanic women. Med Sci Sports Exerc 2011:43:639-46.

245 Saftlas AF, Logsden-Sackett N, Wang W, et al. Work, leisure-time physical activity, and risk of preeclampsia and gestational hypertension. Am J Epidemiol 2004; $160: 758-65$

246 Barakat R, Pelaez M, Cordero Y, et al. Exercise during pregnancy protects against hypertension and macrosomia: randomized clinical trial. Am J Obstet Gynecol 2015. 
247 Katz VL, Ryder RM, Cefalo RC, et al. A comparison of bed rest and immersion for treating the edema of pregnancy. Obstet Gynecol 1990;75:147-51.

248 Kent T, Gregor J, Deardorff L, et al. Edema of pregnancy: a comparison of water aerobics and static immersion. Obstet Gynecol 1999;94(Pt 1):726-9.

249 Hartmann $S$, Huch R. Response of pregnancy leg edema to a single immersion exercise session. Acta Obstet Gynecologica Scand 2005;84:1150-3.

250 Kaaja R, Ronnemaa T. Gestational diabetes: pathogenesis and consequences to mother and offspring. Rev Diabet Stud 2008;5:194-202.

251 Kim C. Gestational diabetes: risks, management, and treatment options. Int J Womens Health 2010;2:339-51.

252 Chasan-Taber L, Marcus BH, Stanek E III, et al. A randomized controlled trial of prenatal physical activity to prevent gestational diabetes: design and methods. J Womens Health (Larchmt) 2009;18:851-9.

253 Oken E, Ning Y, Rifas-Shiman SL, et al. Associations of physical activity and inactivity before and during pregnancy with glucose tolerance. Obstet Gynecol 2006;108:1200-7

254 Retnakaran R, Qi Y, Sermer M, et al. Pre-gravid physical activity and reduced risk of glucose intolerance in pregnancy: the role of insulin sensitivity. Clin Endocrinol (Oxf) 2009;70:615-22.

255 Russo LM, Nobles C, Ertel KA, et al. Physical activity interventions in pregnancy and risk of gestational diabetes mellitus: a systematic review and meta-analysis. Obstet Gynecol 2015;125:576-82

256 Dempsey JC, Sorensen TK, Williams MA, et al. Prospective study of gestational diabetes mellitus risk in relation to maternal recreational physical activity before and during pregnancy. Am J Epidemiol 2004;159:663-70.

257 Dempsey JC, Williams MA, Leisenring WM, et al. Maternal birth weight in relation to plasma lipid concentrations in early pregnancy. Am J Obstet Gynecol 2004:190:1359-68.

258 Cheung NW. The management of gestational diabetes. Vasc Health Risk Manag 2009:5:153-64

259 Karagiannis T, Bekiari E, Manolopoulos K, et al. Gestational diabetes mellitus: why screen and how to diagnose. Hippokratia 2010;14:151-4.

260 Poyhonen-Alho MK, Teramo KA, Kaaja RJ, et al. 50gram oral glucose challenge test combined with risk factor-based screening for gestational diabetes. Eur J Obstet Gynecol Reprod Biol 2005;121:34-7.

261 Griffin ME, Coffey M, Johnson $\mathrm{H}$, et al. Universal vs. risk factor-based screening for gestational diabetes mellitus: detection rates, gestation at diagnosis and outcome. Diabet Med 2000;17:26-32.

262 Hegaard HK, Pedersen BK, Nielsen BB, et al. Leisure time physical activity during pregnancy and impact on gestational diabetes mellitus, pre-eclampsia, preterm delivery and birth weight: a review. Acta Obstet Gynecol Scand 2007;86:1290-6.

263 Iqbal R, Rafique $G$, Badruddin $S$, et al. Increased body fat percentage and physical inactivity are independent predictors of gestational diabetes mellitus in South Asian women. Eur J Clin Nutr 2007;61:736-42.

$264 \mathrm{Hu} F \mathrm{BB}, \mathrm{Li}$ TY, Colditz GA, et al. Television watching and other sedentary behaviors in relation to risk of obesity and type 2 diabetes mellitus in women. JAMA 2003;289:1785-91.

265 American College of Sports Medicine. Impact of physical activity during pregnancy and postpartum on chronic disease risk. Med Sci Sports Exerc 2006;38:989-1006.

266 Tomkins CC, Mottola MF, Giroux I. Dietary intake, capillary blood glucose, and activity level of activity-restricted, hospitalized, pregnant women in the third trimester: a pilot study. Appl Physiol Nutr Metab 2007;32:1105-14.

267 US Surgeon General. Physical activity and health; a report of the surgeon general. Atlanta: US Department of Health and Human Services, CDC, National Center for Disease Control and Prevention, 1996.

268 Carpenter MW. Gestational diabetes, pregnancy hypertension, and late vascular disease. Diabetes Care 2007;30(Suppl 2):S246-50.

269 Barakat R, Pelaez M, Lopez C, et al. Exercise during pregnancy and gestational diabetes-related adverse effects: a randomised controlled trial. Br J Sports Med 2013;47:630-6

270 Vleeming A, Albert HB, Ostgaard HC, et al. European guidelines for the diagnosis and treatment of pelvic girdle pain. Eur Spine J 2008;17:794-819.

271 Ostgaard HC, Zetherstrom G, Roos-Hansson E, et al. Reduction of back and posterior pelvic pain in pregnancy. Spine 1994;19:894-900.

272 Robinson HS, Mengshoel AM, Veierod MB, et al. Pelvic girdle pain: potential risk factors in pregnancy in relation to disability and pain intensity three months postpartum. Man Ther 2010;15:522-8.

273 Gutke A, Ostgaard HC, Oberg B. Pelvic girdle pain and lumbar pain in pregnancy: a cohort study of the consequences in terms of health and functioning. Spine (Phila Pa 1976) 2006;31:E149-55.

274 Stuge B, Laerum E, Kirkesola G, et al. The efficacy of a treatment program focusing on specific stabilizing exercises for pelvic girdle pain after pregnancy: a randomized controlled trial. Spine 2004:29:351-9.

275 O'Sullivan PB, Beales DJ. Diagnosis and classification of pelvic girdle pain disorders—part 1: a mechanism based approach within a biopsychosocial framework. Man Ther 2007;12:86-97.

276 Bjorklund K, Bergstrom S. Is pelvic pain in pregnancy a welfare complaint? Acta Obstet Gynecol Scand 2000;79:24-30.
277 Charpentier K, Leboucher J, Lawani M, et al. Back pain during pregnancy and living conditions: a comparison between Beninese and Canadian women. Ann Phys Rehabil Med 2012;55:148-59.

278 Mousavi SJ, Parnianpour M, Vleeming A. Pregnancy related pelvic girdle pain and low back pain in an Iranian population. Spine (Phila Pa 1976) 2007;32:E100-4.

279 Wormslev M, Juul AM, Marques B, et al. Clinical examination of pelvic insufficiency during pregnancy. An evaluation of the interobserver variation, the relation between clinical signs and pain and the relation between clinical signs and physical disability. Scand J Rheumatol 1994;23:96-102.

280 Wu WH, Meijer OG, Uegaki K, et al. Pregnancy-related pelvic girdle pain (PPP), I: terminology, clinical presentation, and prevalence. Eur Spine J 2004;13:575-89.

281 Eichenseer PH, Sybert DR, Cotton JR. A finite element analysis of sacroiliac joint ligaments in response to different loading conditions. Spine (Phila Pa 1976) 2011;36:E1446-52.

282 Snijders CJ, Vleeming A, Stoeckart R. Transfer of lumbosacral load to iliac bones and legs - part 2: loading of the sacroiliac joints when lifting in a stooped posture. Clin Biomech (Bristol, Avon) 1993;8:295-301.

283 Snijders CJ, Vleeming A, Stoeckart R. Transfer of lumbosacral load to iliac bones and legs-part 1: biomechanics of self-bracing of the sacroiliac joints and its significance for treatment and exercise. Clin Biomech (Bristol, Avon) 1993;8:285-94.

284 Palsson TS, Beales D, Slater H, et al. Pregnancy is characterized by widespread deep-tissue hypersensitivity independent of lumbopelvic pain intensity, a facilitated response to manual orthopedic tests, and poorer self-reported health. $J$ Pain 2015;16:270-82.

285 Palsson TS, Graven-Nielsen T. Experimental pelvic pain facilitates pain provocation tests and causes regional hyperalgesia. Pain 2012;153:2233-40.

286 Palsson TS, Hirata RP, Graven-Nielsen T. Experimental pelvic pain impairs the performance during the Active Straight Leg Raise Test and causes excessive muscle stabilization. Clin J Pain 2015;31:642-51.

287 Torstensson T, Lindgren A, Kristiansson P. Corticosteroid injection treatment to the ischiadic spine reduced pain in women with long-lasting sacral low back pain with onset during pregnancy: a randomized, double blind, controlled trial. Spine (Phila Pa 1976) 2009;34:2254-8.

288 Torstensson T, Lindgren A, Kristiansson P. Improved function in women with persistent pregnancy-related pelvic pain after a single corticosteroid injection to the ischiadic spine: a randomized double-blind controlled trial. Physiother Theory Pract 2013:29:371-8.

289 Pennick V, Liddle SD. Interventions for preventing and treating pelvic and back pain in pregnancy. Cochrane Database Syst Rev 2013;(8):CD001139.

290 Haakstad LA, Bo K. Effect of a regular exercise programme on pelvic girdle and low back pain in previously inactive pregnant women: a randomized controlled trial. J Rehabil Med 2015;47:229-34.

291 Eggen MH, Stuge B, Mowinckel P, et al. Can supervised group exercises including ergonomic advice reduce the prevalence and severity of low back pain and pelvic girdle pain in pregnancy? A randomized controlled trial. Phys Ther 2012:92:781-90.

292 Morkved S, Salvesen KA, Schei B, et al. Does group training during pregnancy prevent lumbopelvic pain? A randomized clinical trial. Acta Obstet Gynecol Scand 2007;86:276-82.

293 Stafne SN, Salvesen KA, Romundstad PR, et al. Does regular exercise during pregnancy influence lumbopelvic pain? A randomized controlled trial. Acta Obstet Gynecol Scand 2012;91:552-9.

294 Mogren IM. Previous physical activity decreases the risk of low back pain and pelvic pain during pregnancy. Scand J Public Health 2005;33:300-6.

295 Haakstad L, Telenius E, Bø K. Exercise and pelvic girdle pain during pregnancy. Are there any associations? Open I Obstet Gynecol 2013;3:520-7.

296 Owe KM, Bjelland EK, Stuge B, et al. Exercise level before pregnancy and engaging in high-impact sports reduce the risk of pelvic girdle pain: a population-based cohort study of 39184 women. Br I Sports Med Published Online First: 4 October 2015 doi:10.1136/bjsports-2015-094921

297 Thorell E, Kristiansson P. Pregnancy related back pain, is it related to aerobic fitness? A longitudinal cohort study. BMC Pregnancy Childbirth 2012;12:30.

298 Bump RC, Norton PA. Epidemiology and natural history of pelvic floor dysfunction. Obstet Gynecol Clin North Am 1998;25:723-46.

299 Haylen BT, de Ridder D, Freeman RM, et al. An International Urogynecological Association (IUGA)/International Continence Society (ICS) joint report on the terminology for female pelvic floor dysfunction. Neurourol Urodyn 2010:29:4-20

300 Milsom I, Altman D, Cartwright R, et al. Epidemiology of urinary incontinence (UI) and other lower urinary tract symptoms (LUTS), pelvic organ prolapse (POP) and anal incontinence. In: Abrams P, Cardozo L, Khoury A, et al. Incontinence. 5th edn. Health Publication Ltd, Committee 1, 2013:15-107.

301 Bo K, Hilde G, Staer-Jensen J, et al. Does general exercise training before and during pregnancy influence the pelvic floor "opening" and delivery outcome? A 3D/4D ultrasound study following nulliparous pregnant women from mid-pregnancy to childbirth. Br J Sports Med 2015;49:196-9. 
302 Caylet N, Fabbro-Peray P, Mares P, et al. Prevalence and occurrence of stress urinary incontinence in elite women athletes. Can J Urol 2006;13:3174-9.

303 Johannessen HH, Morkved S, Stordahl A, et al. Anal incontinence and quality of life in late pregnancy: a cross-sectional study. Br I Obstet Gyneacol 2014;121:978-87.

304 Johannessen HH, Wibe A, Stordahl A, et al. Prevalence and predictors of anal incontinence during pregnancy and 1 year after delivery: a prospective cohort study. Br J Obstet Gyneacol 2014;121:269-79.

305 Vitton V, Baumstarck-Barrau K, Brardjanian S, et al. Impact of high-level sport practice on anal incontinence in a healthy young female population. J Womens Health (Larchmt) 2011;20:757-63.

306 Larsen WI, Yavorek T. Pelvic prolapse and urinary incontinence in nulliparous college women in relation to paratrooper training. Int Urogynecol I Pelvic Floor Dysfunct 2007;18:769-71.

307 Koelbl H, Igawa T, Salvatore $S$, et al. Pathophysiology of urinary incontinence, faecal incontinence and pelvic organ prolapse. In: Abrams P, et al, eds. Incontinence: Committee 4. 2013:261-359.

308 Delancey JO, Kane Low L, Miller JM, et al. Graphic integration of causal factors of pelvic floor disorders: an integrated life span model. Am J Obstet Gynecol 2008;199:610.e1-5

309 Nygaard IE, Thompson FL, Svengalis SL, et al. Urinary incontinence in elite nulliparous athletes. Obstet Gynecol 1994;84:183-7.

310 Nygaard IE, Rao SS, Dawson JD. Anal incontinence after anal sphincter disruption: a 30-year retrospective cohort study. Obstet Gynecol 1997;89:896-901.

311 Bo K, Sundgot-Borgen J. Are former female elite athletes more likely to experience urinary incontinence later in life than non-athletes? Scand I Med Sci Sports 2010;20:100-4
312 Eliasson $\mathrm{K}$, Larsson T, Mattsson E. Prevalence of stress incontinence in nulliparous elite trampolinists. Scand J Med Sci Sports 2002;12:106-10.

313 Cottenden A, Bliss D, Buckley B, et al. Management using continence products. In: Abrams P, Cardozo L, Khoury S, et al, eds. Incontinence. 5th edn. Committee 20, 2015:1651-786.

314 Glavind K. Use of a vaginal sponge during aerobic exercises in patients with stress urinary incontinence. Int Urogynecol I Pelvic Floor Dysfunct 1997;8:351-3.

315 Boyle R, Hay-Smith EJ, Cody JD, et al. Pelvic floor muscle training for prevention and treatment of urinary and faecal incontinence in antenatal and postnatal women. Cochrane Database Syst Rev 2012;(10):CD007471.

316 Dinc A, Kizilkaya Beji N, Yalcin O. Effect of pelvic floor muscle exercises in the treatment of urinary incontinence during pregnancy and the postpartum period. Int Urogynecol J Pelvic Floor Dysfunct 2009;20:1223-31.

317 Venes D, Taber CW. Taber's cyclopedic medical dictionary. 22nd edn. Philadelphia: FA Davis Co, 2013.

318 Boissonnault JS, Blaschak MJ. Incidence of diastasis recti abdominis during the childbearing year. Phys Ther 1988;68:1082-6.

319 Fernandes da Mota PG, Pascoal AG, Carita Al, et al. Prevalence and risk factors of diastasis recti abdominis from late pregnancy to 6 months postpartum, and relationship with lumbo-pelvic pain. Man Ther 2015;20:200-5.

320 Mota P, Pascoal AG, Sancho F, et al. Reliability of inter-rectus distance measured by palpation. Comparison of palpation and ultrasound measurements. Manual Therapy 2013;18:294-8.

321 Benjamin DR, van de Water AT, Peiris CL. Effects of exercise on diastasis of the rectus abdominis muscle in the antenatal and postnatal periods: a systematic review. Physiotherapy 2014;100:1-8. 